pag

Business School

WORKING PAPER SERIES

Working Paper

$$
\text { 2014-325 }
$$

Volatility forecasting and risk management for commodity markets in the presence of asymmetry and long memory

Walid Chkili

Shawkat Hammoudeh

Duc Khuong Nguyen

http://www.ipag.fr/fr/accueil/la-recherche/publications-WP.html

IPAG Business School

184, Boulevard Saint-Germain

75006 Paris

France 


\title{
Volatility forecasting and risk management for commodity markets in the presence of asymmetry and long memory
}

\author{
Walid Chkili ${ }^{\mathrm{a}}$, Shawkat Hammoudeh ${ }^{\mathrm{b}}$, and Duc Khuong Nguyen ${ }^{\mathrm{c}, *}$ \\ ${ }^{\mathrm{a}}$ School of Business, Manouba University and International Finance Group, Tunisia \\ walid.chkili@,fsegt.rnu.tn \\ ${ }^{b}$ Lebow College of Business, Drexel University, 3141 Chestnut Street, Philadelphia, PA 19104, USA \\ hammousm@drexel.edu \\ ${ }^{c}$ IPAG Lab, IPAG Business School, 184 Boulevard Saint-Germain, 75006 Paris, France \\ duc.nguyen@ipag.fr \\ * Corresponding author
}

\begin{abstract}
This paper explores the relevance of asymmetry and long memory in modeling and forecasting the conditional volatility and market risk of four widely traded commodities (crude oil, natural gas, gold, and silver). A broad set of the most popular linear and nonlinear GARCH-type models is used to investigate this relevancy. Our in-sample and out-of-sample results show that volatility of commodity returns can be better described by nonlinear volatility models accommodating the long memory and asymmetry features. In particular, the FIAPARCH model is found to be the best suited for estimating the VaR forecasts for both short and long trading positions. This model also gives for all four commodities the lowest number of violations under the Basel II Accord rule, given a risk exposure at the $99 \%$ confidence level. Several implications for commodity market risks, policy regulations and hedging strategies can be drawn from the obtained results.
\end{abstract}

Keywords: commodity markets, GARCH models, asymmetries, long memory, volatility forecasts. JEL Classifications: C22, G17, Q47 


\section{Introduction}

The literature on commodities has concentrated mainly on price co-movements and information transmission between returns. On the other hand, the research on conditional commodity return volatility and market risk has been less generous than the counterpart on commodity prices and returns. However, studies focusing on commodity volatility have been gaining importance due to rising volatility and the increasing role commodities play in the international asset markets (e.g., Regnier, 2007; Dahl and Iglesias, 2009; Vivian and Wohar, 2012; Kang and Yoon, 2013, Creti et al., 2013; Thuraisamy et al., 2013). The increased interest is also due to the fact that commodity returns possess empirical stylized characteristics such as nonnormal distribution, asymmetry, structural breaks and fat tails that affect model performance (e.g., Hung et al., 2008; Cheong, 2009; Aloui and Mabrouk, 2010; Cheng and Hung, 2011), and thereby require experimentation with different volatility models. The traditional strand of research on commodity volatility largely addresses dynamic volatility behavior of a single commodity or volatility transmission across several commodities over time, using the standard volatility models. New studies however attempt to accommodate the varying characteristics of volatility of a commodity or a group of commodities in order to come up with a methodological representation that forecasts future volatility of a single commodity or a portfolio more accurately (e.g., Wei et al., 2010; Arouri et al., 2012a,b).

The research on commodity market risks often uses the value-at-risk $(\mathrm{VaR})$ approach based on the Generalized Autoregressive Conditional Heteroscedasticity (GARCH) family models to evaluate the validity and forecasts of volatility models. A model is said to be best suited for modeling the conditional volatility of commodity markets if it provides the most accurate $\operatorname{VaR}$ estimates and forecasts. Since the dust has not been settled and the jury is still out on the suitability of volatility models to model commodity volatility behavior, this article will therefore evaluate the accuracy of various linear and nonlinear models using, in addition to the $V a R$ approach, different evaluation and forecasting criteria. Moreover, there are actually only a few studies that examine the choice between volatility models for commodities markets despite the increasing financialization and volatility of these markets, and they often fall short of adequately characterizing volatility behavior. ${ }^{1}$ The results from this research are of

\footnotetext{
${ }^{1}$ By increasing financialization of commodity markets, we refer to a situation in which commodity prices are determined not only by primary supply and demand conditions, but also by the commodity derivatives trading and financial investors' activity. Several papers have recently addressed the issue of the financialization of commodity markets and its impact on volatility behavior and transmission (Domanski and Heath, 2007; Dwyer et al., 2011; Vivian and Wohar, 2012; Creti et al., 2013; Silvennoinen and Thorp, 2013).
} 
great interest for various economic agents including international investors, energy managers, and policymakers who constantly seek to better understand the volatility dynamics of commodity prices in order to build efficient risk-hedging models as well as to implement sound policies to heed inflation pressure.

More concretely, our first objective is to examine the suitability of GARCH-class models in modeling conditional volatility and market risk $(\mathrm{VaR})$ of four most widely traded commodities (crude oil, natural gas, gold and silver) in the presence of long memory and asymmetric effects. Moreover, these commodities have impacts on real economic activity, financial markets, and financial, economic and geopolitical risks. The importance of the long memory and asymmetry properties has been demonstrated not only for modeling the volatility of commodity volatility but also for improving the accuracy of VaR estimates and forecasts (e.g., Cheong, 2009; Wei et al., 2010; Aloui and Mabrouk, 2010). Our second objective is to compare the out-of-sample predictive performance of competing GARCH models based on commonly-used evaluation criteria and the $V a R$ approach for both portfolio short and long positions. Furthermore, we evaluate the economic importance of our results by computing the Basel II Accord's daily capital requirements for individual commodities, given the VaR estimates derived from competing GARCH models. In comparison with existing studies on volatility forecasting, we consider a broader set of GARCH-type models which includes four linear specifications (GARCH, EGARCH, IGARCH, and RiskMetrics) and three nonlinear specifications (FIGARCH, FIAPARCH and HYGARCH). In comparison with previous studies, our dataset is extended to cover the spot and futures prices of natural gas, gold and silver, in addition to the frequently studied spot and futures price of crude oil (e.g., Sadorsky, 2006; Agnolucci, 2009; Kang et al., 2009; Weil et al., 2010; Arouri et al., 2012b). The choice of these four major commodities (crude oil, natural gas, gold, and silver) is motivated by the fact that they altogether represent the strategic commodities that have significant influences on the real sector, financial sector, and economic growth of national economy (e.g., Hamilton, 1996; Holmes and Wang, 2003; Cologni and Manera, 2009; Browne and Cronin, 2010). Moreover, while past studies have extensively investigated the issue of volatility modeling and forecasting for crude oil and related petroleum products (Wei et al, 2010; Arouri et al., 2012b; and references therein), none of them have extended their samples to include natural gas, gold, and silver at the same time in order to get a comparative view of volatility behavior across these different types of commodities. For instance, Baur and McDermott (2010) provide evidence that gold is both a hedge and a safe haven for major European stock markets and the 
US but not for Australia, Canada, Japan and large emerging markets such as the BRIC countries. Arouri et al. (2012a) investigate the potential of structural change and long memory (LM) properties in returns and volatility of the four major precious metals traded on the COMEX markets (gold, silver, platinum, and palladium) and show evidence that conditional volatility of precious metals is better explained by long memory than by structural breaks.

The paper distinguishes itself from the literature in several ways. The recent literature that deals with commodity markets separates asymmetry from long memory and concentrates more on the former than the latter. Our paper combines both statistical properties for these widely traded commodities, including natural gas which is not researched in the literature as much as crude oil and its refined products are. Moreover, the past research on volatility forecasting for commodity markets is limited as it has focused more on forecasting conditional return than conditional volatility. Our paper conducts conditional volatility forecasts in the presence of asymmetry and dual long memory. It also seeks to find the best suited model for estimating the $\operatorname{VaR}$ forecasts for both short and long trading positions. Finally, it examines the lowest number of violations under the Basel II Accord rule for the four commodities.

Overall, the main contributions of this study are the following: (1) Over the in-sample period, the FIAPARCH is the best suited model in almost all cases, while the standard GARCH model is selected only once; (2) None of the competing models absolutely outperforms the others in terms of volatility forecasts, but the nonlinear GARCH models perform better than the linear models, regardless of the forecasting horizons; and (3) The FIAPARCH provides the best $\operatorname{VaR}$ estimates and forecasts for all commodities at almost all confidence levels. This model also leads to the lowest number of violations (i.e., number of times that actual losses exceed $V a R$ estimates). The foremost implications of our findings have strong bearing to volatility model building for commodity markets. On the other hand, large violations under the Basel II Accord may lead to failures of financial institutions that invest in commodities, as the capital requirements implied by the VaR threshold forecasts may be insufficient to cover the realized losses. Lower than ten violations imply that these models do not lead to entry in the red zone which is important for an institutions' image, reputation, and risk management.

The remainder of the article is structured as follows. Section 2 reviews the major studies focusing on modeling and forecasting of commodity volatility. Section 3 presents the econometric approach. Section 4 describes the data used, while Section 5 reports and discusses the empirical results. The concluding remarks are provided in Section 6. 


\section{Literature review}

There is actually increasing literature that studies the volatility asymmetry of commodities. More recent research attempts to combine in one model more than one volatility characteristic because modeling commodity volatility behavior may entail the incorporation of several characteristics. It may, for example, examine both symmetry or asymmetry and the long memory (LM) of commodity volatility behavior separately or simultaneously (Elder and Serletis, 2008; Wang et al., 2011; Aloui and Mabrouk, 2010). The presence of range dependency in the commodity volatility can be valuable to be recognized in producing forecasts which are important for asset valuation, hedging, and risk management. Choi and Hammoudeh (2009), for instance, find that LM-based univariate GARCH models have better forecasting commodity volatility than the standard GARCH models for oil and refined products markets. There are also studies that consider, in addition to symmetry or asymmetry, structural changes along with long memory for commodity markets (Arouri et al., 2012a,b). It is shown that the volatility of commodity returns is better explained by long memory than by structural breaks. Therefore, modeling LM and volatility characteristics accurately should produce better models that give rise to better forecasting and sounder policy analysis.

McKenzie et al. (2001) study the suitability of the univariate power ARCH (PARCH) model to precious metals traded at the London Metal Exchange (LME), and find that asymmetric effects are not present. Hammoudeh and Yuan (2008) use univariate GARCH-based models to examine the properties of conditional volatility for three important metals (gold, silver, and copper) while controlling for shocks from global oil prices (i.e., WTI) and the three-month US Treasury bill interest rate. They focus particularly on these volatility characteristics: persistence, asymmetric reaction to the good and bad news, and transitory and permanent components. These authors find evidence that the conditional volatility of gold and silver is more persistent, but less sensitive to leverage effects than that of copper.

Hammoudeh et al. (2010) examine the conditional volatility, and correlation dependency and interdependency for the four major precious metals (gold, silver, platinum and palladium), while accounting for geopolitics within a multivariate system. The implications of the estimated results for portfolio designs and hedging strategies are also analyzed. The results for the four metals system show significant short-run and long-run dependencies and interdependencies to news and past volatility. 
Hammoudeh et al. (2004) use a trivariate symmetric BEKK model to examine the volatility between oil prices and U.S. oil industry equity indices. Ewing et al. (2002) employ a bivariate symmetric BEKK model for the oil and natural gas sectors to examine how volatility changes over time and across the two sectors. Chan at al. (2010) utilize both the symmetric VARMA-GARCH and the asymmetric VARMA-AGARCH to examine symmetric volatility spillovers as well as asymmetric cross-effects between spot, forward and futures price returns of four major oil markets. Those authors find significant asymmetries between the two benchmarks, namely WTI and Brent, of the light sweet grade category. They also find asymmetric spillovers from these major markets to two other markets.

Choi and Hammoudeh (2008) test for the presence of long memory in oil and refined products prices' returns, absolute returns, and squared returns using several parametric and semi parametric methods. This study finds strong evidence of long memory (LM) in the absolute and squared spot and futures returns for crude oil, gasoline and heating oil. The FIGARCH model also provides strong evidence of long memory (LM) for most of oil and products price returns. Structural breaks have only the partial effects of slightly reducing persistence for just absolute and squared returns. Examining the forecasting behavior of two competing models, the less parsimonious ARFIMA which satisfies the LM property, and the parsimonious ARMA with short-term processes, the ARFIMA model is found to provide significantly better out-of-sample forecasts at all forecasting horizons for all three petroleum types. Tansuchat et al. (2009) apply the FIGARCH model to produce long memory-based volatility forecasts for agricultural commodities. They find more support for the FIGARCH model over other competing volatility models. Kang et al. (2009) argue that the component GARCH and fractionally integrated GARCH models which capture the long memory volatility yield superior forecast performance compared to the simple GARCH and integrated GARCH models. However, using parametric and nonparametric GARCH models to forecast oil price return volatility, Cheong (2009) finds that the simple GARCH model characterizes the Brent crude oil data better than the GARCH models which accommodate asymmetric and/or long memory volatility, based on the loss functions and Hansen's superior predictive ability test. This author also shows that the out-of-sample volatility forecast of the nonparametric GARCH model yields superior performance compared to an extensive class of parametric GARCH models, based on loss functions and Hansen's superior predictive ability test. More recently, Arouri et al. (2012b) focus on modeling and forecasting petroleum price vola- 
tility and document that the FIGARCH model with structural breaks is the best model when structural change is present.

Vivian and Wohar (2012) use an iterative cumulative sum of squares procedure combined with the GARCH $(1,1)$ model to examine whether there are structural breaks in the spot return volatility of 28 different commodities including energy and precious metals. They find very limited evidence of commodity volatility breaks during the recent financial crisis, compared to the whole sample period that ranges from 1985 to 2010. Structural breaks in commodity volatility are more apparent prior to 2007. Arouri et al. (2012a) explore the potential of structural changes and long memory (LM) properties in returns and volatility of the four major precious metals (gold, silver, platinum and palladium). Their results indicate strong evidence of long-range dependence in the daily conditional return and volatility processes for these precious metals. Moreover, for most of the precious metals considered, this dual long memory is found to be adequately captured by an ARFIMA-FIGARCH model.

Faced with these mixed results, Weil et al. (2010) try to reconcile the findings from different models. They posit a tentative conclusion that the extent of forecast superiority for a particular GARCH model depends on the type of loss functions used to assess the volatility models. This conclusion is however not without critics because the ability of different models to capture the underlying characteristics of the data is not the same and volatility features may also differ across different commodities. Moreover, since volatility forecasts are usually employed to estimate the market risk embedded in a single commodity or a portfolio of commodities, the best volatility models can be selected on the basis of the accuracy of market risk forecasts they produce. In this case, a common market risk measure, such as $V a R$, should be chosen, thus avoiding the problem of multiple loss functions.

As indicated earlier, we consider in this study a broader set of GARCH-type models and our dataset is extended to also cover spot and futures prices of natural gas, gold and silver, in addition to the spot and futures price of crude oil. In total, our study focuses on seven volatility models and eight prices of commodities. We also rely on the VaR approach to select the best suited model for each commodity included in our analysis. This approach allows for not only checking the robustness of the results obtained from the forecasting evaluation criteria, but also shows how the resulting volatility estimates and forecasts can be used to measure the commodity market risk. We finally show how to choose between the competing models based on calculations of out-of-sample percentage of violations and daily capital charges that 
financial institutions must report to financial market regulatory authorities, in compliance with the Basel II Accord rules.

\section{Empirical Methodology}

Long memory and volatility asymmetry are now recognized as common characteristics of commodity returns. Volatility asymmetry occurs when negative shocks have stronger impacts on volatility process than positive shocks. It mainly arises during periods of severe financial stress like the recent financial crises. As to long memory, it refers to the low decay rates of long-lag autocorrelations and principally takes root in the problem of aggregation of multiple macroeconomic variables (e.g., demand, supply, industrial activity, monetary policy, and regulation) that may persist over time. Arouri et al. (2012b) also argue that long memory in energy prices may exist when price changes partially cancel themselves out, while the original shock takes a long time to work through the system. The most obvious implication of long memory is the potential of time-series predictability which ultimately implies the invalidity of weak-form informational efficiency of the markets under consideration (Elder and Serletis, 2008). A finding of a large long memory coefficient may also indicate that the commodity has long positive or negative strays from equilibrium.

This section presents the empirical framework which we use to explore the dynamics of volatility in presence of both long memory and asymmetric effects for the eight spot and futures returns of the four major commodities under consideration. We consider four linear GARCH models (GARCH, IGARCH, EGARCH, and RiskMetrics) and three nonlinear models (FIGARCH, FIAPARCH, and HYGARCH) as competing candidate models. They are widely used in the related literature and their statistical performance and suitability have been recognized in previous studies (e.g., Kang et al., 2009; Arouri et al., 2012b). While the first group of models serves as baseline models as they enable to separately capture the volatility persistence, asymmetry, and infinite persistence, the second group takes either the long memory or simultaneously the asymmetry and long memory features into account. We then show how evaluation criteria and the VaR approach can be used to compare the out-of-sample forecasting performance of these volatility models. Similarly to the majority of previous studies (e.g., Sadorsky, 2006; Mohammadi and Su, 2010; Wang et al., 2011), we model the conditional mean by an autoregressive process of order one and adopt the $\operatorname{GARCH}(1,1)$ class models for the purpose of performance comparison as this specification is chosen by commonly- 
used information criteria (AIC and BIC) for almost all series of the commodity spot and futures prices we consider. ${ }^{2}$

\subsection{Linear GARCH-class models}

Since its apparition, the standard GARCH model developed by Bollerslev (1986) has become one of the most popular models for describing the time-varying clustering volatility of financial returns. In this study, GARCH-type models are also used to investigate the characteristics of commodity market returns.

Let $r_{t}$ be the commodity return series, the standard $\operatorname{GARCH}(1,1)$ is represented by

$$
\begin{aligned}
& r_{t}=\mu_{t}+\varepsilon_{t} \\
& \varepsilon_{t}=\sigma_{t} z_{t}, z_{t} N I D \sim(0,1) \\
& \sigma^{2}=\omega+\alpha \varepsilon_{t-1}^{2}+\beta \sigma_{t-1}^{2}
\end{aligned}
$$

where $\mu_{t}$ and $\sigma_{t}^{2}$ denote respectively the conditional mean and the conditional variance of commodity returns. The conditional variance process is positive and stationary if the following conditions hold: $\omega>0, \alpha>0, \beta>0$ and $\alpha+\beta<1$.

We also consider three alternative models to this linear GARCH model: the Integrated GARCH (IGARCH) model proposed by Engle and Bollerslev (1986), the RiskMetrics volatility model introduced by J.P. Morgan in 1992, and the Exponential GARCH (EGARCH) of Nelson (1991). The IGARCH is a special case of the GARCH model when $\alpha+\beta=1$, and is thus suitable for capturing infinite persistence in the conditional variance. The RiskMetrics model can be viewed as a simple specification of the IGARCH model when the ARCH and GARCH parameters are set equal to 0.06 and 0.94 , respectively. Formerly, the RiskMetrics methodology for volatility modeling is given by

$$
\sigma^{2}=0.06 \varepsilon_{t-1}^{2}+0.94 \sigma_{t-1}^{2}
$$

The EGARCH model of Nelson (1991) specifies the asymmetric responses to the negative and positive news, and is given $b^{3}$

$$
\log \left(\sigma_{t}^{2}\right)=\omega+\alpha\left[\left|\frac{\varepsilon_{t-1}}{\sqrt{\sigma_{t-1}^{2}}}\right|-\sqrt{2 / \pi}\right]+\beta \log \left(\sigma_{t-1}^{2}\right)+\delta \frac{\varepsilon_{t-1}}{\sqrt{\sigma_{t-1}^{2}}}
$$

\footnotetext{
${ }^{2}$ The results of the lag-length specification tests for conditional variance processes are not reported here to conserve space, but can be made entirely available upon request addressed to the corresponding author.

${ }^{3}$ Negative shocks will have more impacts on the volatility than positive shocks of equal magnitude if $\delta \prec 0$.
} 


\subsection{Nonlinear GARCH-class models}

Since the prices of some commodities, particularly those of crude oil, have experienced long swings and frequent instabilities over the last decades (Arouri et al., 2012b; Vivian and Wohar, 2012), it is possible that their conditional volatility reacts to shocks in a nonlinear fashion. This nonlinearity feature of commodity return volatility has been demonstrated in several recent studies (Ewing et al., 2002; Hammoudeh and Yuan, 2008; Cochran et al., 2012). It is thus expected that nonlinear volatility models may perform better than linear volatility models which we presented previously. Our study also considers three nonlinear GARCH-class models: FIGARCH, FIAPARCH and HYGARCH. These nonlinear models mainly differ from the linear ones in that they capture two additional important features of financial time series' volatility, namely the long memory and volatility asymmetry.

The fractional integrated GARCH (FIGARCH) model, developed by Baillie et al. (1996), allows us to model a slow decay of volatility (long memory behavior) as frequently seen in practice, as well as to distinguish between the long memory and short memory in the conditional variance. Formally, the $\operatorname{FIGARCH}(1, d, 1)$ can be defined as follows

$$
\sigma_{t}^{2}=\omega+\beta \sigma_{t-1}^{2}+\left[1-\left(1-\beta L^{-1}\right)(1-\lambda L)(1-L)^{d}\right] \varepsilon_{t}^{2}
$$

where $\omega>0, \beta \prec 1$, and $\lambda<1$. The parameter $d$ is the fractional integration parameter reflecting the degree of long memory or the persistence of shocks to conditional variance, and satisfies the condition $0 \leq d \leq 1$. If $0<d<1$, the model implies an intermediate range of persistence and the volatility shocks dissipate following a hyperbolic rate of decay. If $d=0$, the model has a short memory and reduces to the $\operatorname{GARCH}(1,1)$ model. If $d=1$, model becomes an $\operatorname{IGARCH}(1,1)$ whose variance process is no longer mean-reverting.

Tse (1998) proposes the fractional integrated asymmetric power ARCH (FIAPARCH) model which explicitly accommodates both long memory and asymmetry effects in the conditional volatility. The FIAPARCH( $1, d, 1)$ takes the following form

$$
\sigma_{t}^{\delta}=\omega(1-\beta L)^{-1}+\left[1-(1-\beta L)^{-1}(1-\lambda L)(1-L)^{d}\right]\left(\left|\varepsilon_{t}\right|-\gamma \varepsilon_{t}\right)^{\delta}
$$

where $\omega \succ 0, \delta>0, \beta \prec 1$, and $\lambda<1$. The parameter $\gamma$ refers to the asymmetric parameter satisfying the condition $-1<\gamma<1$. Negative shocks will have more impact on commodity return volatility than positive shocks of equal magnitude when $\gamma>0$. As in the FIGARCH model, the fractional integration parameter $d, 0 \leq d \leq 1$, in the FIAPARCH captures the patterns of long memory property in the conditional variance process. The FIAPARCH model 
reduces to the FIGARCH model when $\gamma=0$ and $\delta=2$. When $d=0$, the variance process in Eq. (5) reduces to the APARCH model. Conrad et al. (2011) note that a sufficient condition for the conditional variance of the FIAPARCH model to be positive almost surely for all $t$ is that $\gamma>-1$ and the parameter combination $(\lambda, d, \beta)$ satisfies the inequality constraints presented in Conrad and Haag (2006).

Davidson (2004) generalizes the FIGARCH model to develop the hyperbolic GARCH (HYGARCH) model. The latter allows for modeling the long memory property with hyperbolic convergence rates. The HYGARCH$(1, d, 1)$ model is given by

$$
\sigma_{t}^{2}=\omega+\left[1-(1-\beta L)^{-1} \lambda L\left\{1+\alpha\left((1-L)^{d}-1\right)\right\}\right] \varepsilon_{t}^{2}
$$

where $L$ is the $\log$ operator, $\omega>0, \alpha \geq 0, \beta \prec 1, \lambda<1$, and $0 \leq d \leq 1$. Davidson (2004) shows that the HYGARCH permits the existence of the second moment at more extreme amplitudes than the simple IGARCH and FIGARCH do. It nests the stable GARCH and FIGARCH models when $\alpha=0$ and $\alpha=1$, respectively. The volatility process is stationary when $0 \prec \alpha \prec 1$, but becomes nonstationary when $\alpha \succ 1$. This model is, however, not suitable for capturing the potential of volatility asymmetric effects.

\subsection{Choosing between models}

\subsubsection{Forecasting evaluation based on loss functions}

Forecast evaluations are a vital component of empirical studies that use time series because good forecasts are valuable for decision making. A model is said to be superior to another model if it provides more accurate forecasts. We use two formal loss functions, the Mean Absolute Percentage Error (MAPE) and the Mean Absolute Error (MAE), to evaluate the out-ofsample forecasting performance of the seven competing GARCH-type models used for examining the commodity return volatility. They are defined as

$$
\begin{aligned}
& M A P E=\sqrt{n^{-1} \sum_{t=1}^{n}\left(\sigma_{a, t}^{2}-\sigma_{f, t}^{2}\right)^{2}} \\
& M A E=n^{-1} \sum_{t=1}^{n}\left|\sigma_{a, t}^{2}-\sigma_{f, t}^{2}\right|
\end{aligned}
$$

where $n$ is the number of forecasting data points. $\sigma_{a, t}^{2}$ and $\sigma_{f, t}^{2}$ refer to the realized (actual) volatility and the volatility forecast from a particular GARCH, respectively. Following previous studies (e.g., Kang et al., 2009; Arouri et al., 2012b), the rolling forecasting methodology is employed to generate the one- and twenty-day out-of-sample forecasts of the seven compet- 
ing volatility models. The model that has the smallest mean losses is the best one for forecasting the volatility of commodity returns.

\subsubsection{The VaR approach}

While holding a portfolio of commodities, the investors are exposed to commodity market risks which originate from the sensitivity of commodity returns to market-wide fluctuations. These investors would thus be interested in determining the market risk level of their investment. In this case, the use of the VaR model is particularly useful. First, this approach allows us to measure the market risk associated with different individual commodity assets (or portfolios), i.e., the highest possible loss that a portfolio experiences given a confidence level and a time horizon. Second, it permits to compare the $V a R$ forecast accuracy across volatility models. In our study, we consider both long and short trading positions, and estimate the $\mathrm{VaR}$ for the commodity market returns over the in-sample and out-of-sample periods. In the case of the long trading positions, the risk comes from a drop in the price of the asset because traders bought the asset and are concerned by unfavorable price movements. Inversely, traders face losses when asset price increases in the case of the short positions because they are short on their asset and would have to buy it back at a higher price.

Following past studies on $\operatorname{VaR}$ forecast accuracy (e.g., Giot and Laurent, 2003; Tang and Shieh, 2006), the daily $\operatorname{VaR}$ s for long (buy) and short (sell) trading positions (i.e., $\operatorname{VaR}_{L, t}$ and $\left.V a R_{s, t}\right)$ at time $t$ under normal distribution can be written respectively as follows

$$
\operatorname{VaR}_{L, t}=\hat{\mu}_{t}+z_{\alpha} \hat{\sigma}_{t} \text { and } \operatorname{VaR} R_{S, t}=\hat{\mu}_{t}+z_{1-\alpha} \hat{\sigma}_{t}
$$

where $z_{\alpha}$ designates the left quantile at $\alpha \%$ of the normal distribution and $z_{1-\alpha}$ the right quantile at $\alpha \%$. $\hat{\mu}_{t}$ and $\hat{\sigma}_{t}$ refer to the estimated daily conditional mean and standard deviation of the commodity returns, obtained from a GARCH-based model. When assuming a Student- $t$ distribution, the $\operatorname{VaRs}$ for long and short trading positions are given respectively by

$$
\operatorname{VaR}_{L, t}=\hat{\mu}_{t}+s t_{\alpha, v} \hat{\sigma}_{t} \text { and } \operatorname{VaR} R_{s, t}=\hat{\mu}_{t}+s t_{1-\alpha, v} \hat{\sigma}_{t}
$$

where $s t_{\alpha, v}$ and $s t_{1-\alpha, v}$ are the left and the right quantiles at $\alpha \%$ for the Student- $t$ distribution with $v$ degrees of freedom. We replace $\hat{\mu}_{t}$ and $\hat{\sigma}_{t}$ in Eqs. (9)- (10) by their daily forecasts to estimate the out-of-sample $\operatorname{VaR}$ (or one-day-ahead $\operatorname{VaR}$ estimated at time $t$-1). 
For each commodity return series, we compute the $V a R$ at several pre-specified significance levels of $\alpha \%$ ranging from $5 \%$ to $0.25 \%$. We then examine the performance of the considered GARCH-VaR models by calculating the empirical failure rate for the left and right tails of the return distributions. Here the failure rate is defined as the number of times the commodity return series exceeds the estimated value of $\mathrm{VaR}$. If the failure rate is equal to the pre-specified $\operatorname{VaR}$ level, we can then conclude that the associated VaR model is correctly specified. This hypothesis is explicitly tested by using the Kupiec Likelihood Ratio (LR) test (Kupiec, 1995). The statistic of the Kupiec LR test is given by

$$
L R=-2 \ln \left[\alpha^{T-N}(1-\alpha)^{N}\right]+2 \ln \left[(1-f)^{T-N} f^{T}\right]
$$

where $f$ denotes the empirical failure rate calculated as the ratio of the number of return observations exceeding the estimated $\operatorname{VaR}$ value $(N)$ to the sample size $(T)$, and $\alpha$ is the prespecified $V a R$ level. The Kupiec LR statistic is asymptotically chi-squared distributed with one level of freedom under the null hypothesis that the failure rate $f$ equals the pre-specified $\alpha$.

\subsubsection{VaR and Basel capital charges}

The current framework of the Basel II Accord has made in 1996 two important amendments regarding the treatment of market risk which are largely overlooked in the Basel I Accord (Basel Committee on Banking Supervision, 1996, 2004). It does not only establish the VaR as the official measure of market risk but also allows financial institutions to employ the Internal Model Approach to determine their market risk minimum capital requirements from their own $V a R$ estimates. Here financial institutions are concerned by the $\operatorname{VaR}$ related to the downside risk arising from the fall in the price of financial assets they hold. Whether the internal models used to forecast the $V a R$ are accurate is therefore of paramount importance, particularly in view of serious problems of shortfall provisions in capital levels of most financial institutions following the advent of the U.S. subprime crisis in 2007 and subsequently the 2008-2009 global financial crisis.

Table 1

The three-zone approach of the Basel II Accord for penalty structure

\begin{tabular}{lcc}
\hline Zone & Number of violations & $k$ \\
\hline Green & $0-4$ & 0.00 \\
Yellow & 5 & 0.40 \\
& 6 & 0.50 \\
& 7 & 0.65 \\
& 8 & 0.75 \\
& 9 & 0.85 \\
Red & $10+$ & 1.00 \\
\hline
\end{tabular}

Notes: the number of violations is given for a forecasting period of 250 days. 
More explicitly, under the Basel II Accord, the VaR forecasts of the banks must be reported to the appropriate regulatory authority at the beginning of the day, and are then compared to actual returns at the end of the day. In practice, banks use these forecasts to compute the amount of capital requirements (i.e., daily capital charges) utilized to provide a cushion against adverse market conditions. The Basel II Accord stipulates that the daily capital charge must be set at the higher of the previous day's VaR or the average VaR over the last 60 business days, multiplied by a scaling factor according to the three-zone approach (Table 1). The scaling factor is the sum of 3 and the multiplicative factor $(k)$ as defined in Table 1 . The $k$ factor ranges from 0 to 1 depending on the ex post performance of the $V a R$ model. It indeed corresponds to the penalties that the Basel II Accord imposes on banks using models that lead to a greater number of violations than would be expected, given the specified confidence level of $99 \%$. Formally, the risk-capital charges on a daily basis are defined as follows

$$
\mathrm{DCC}_{\mathrm{t}+1}=\operatorname{Max}\left\{(3+k) \overline{\operatorname{VaR}_{60}}, \operatorname{VaR}_{\mathrm{t}}\right\}
$$

where $\mathrm{DCC}_{\mathrm{t}+1}$ designates the daily capital charges at day $t+1$. The $V a R_{\mathrm{t}}$ refers to value-at-risk for day $t$, derived for long trading positions using the different GARCH-type models we consider. $\overline{V a R_{60}}$ is the average $\operatorname{VaR}$ over the previous 60 working days. $0 \leq k \leq 1$ refers to a violation penalty presented in Table 1. Essentially, the greater the number of the violations when the actual loss exceeds the daily $\operatorname{VaR}$ forecast during the last 250 trading days, the higher the value of the multiplicative factor. As far as the choice between models is concerned, we note that the best GARCH-VaR model is thus the one that produces the lowest violations as specified by the Basel II regulatory framework.

\section{Data}

Our data include the daily spot and three-month futures prices of the four major commodities traded at international exchanges, which are: WTI crude oil (\$/barrel), Henry Hub natural gas (\$/MMBTU), gold (\$/Troy ounce) and silver (\$/Troy ounce). The crude oil and natural gas data were obtained from the U.S. Energy Information Administration database, while the data for precious metals are sourced from the COMEX in New York and extracted from Bloomberg. All the data are collected over the period from January 7, 1997 to March 31, 2011. We intend to cover the late 1990s global recession due to the Asian financial crisis, several subperiods of economic growth and the last global financial crisis. Also, the prices of the considered commodities seem to follow a distinct dynamic pattern as compared to their evolution 
before 1997. Our in-sample period runs from January 7, 1997 to December 31, 2009, while the out-of-sample period runs from January 1, 2010 to March 31, 2011. We calculate the commodity returns by taking the natural logarithm of the ratio of two consecutive prices.

\section{Figure 1}

Dynamics of commodity spot and futures prices
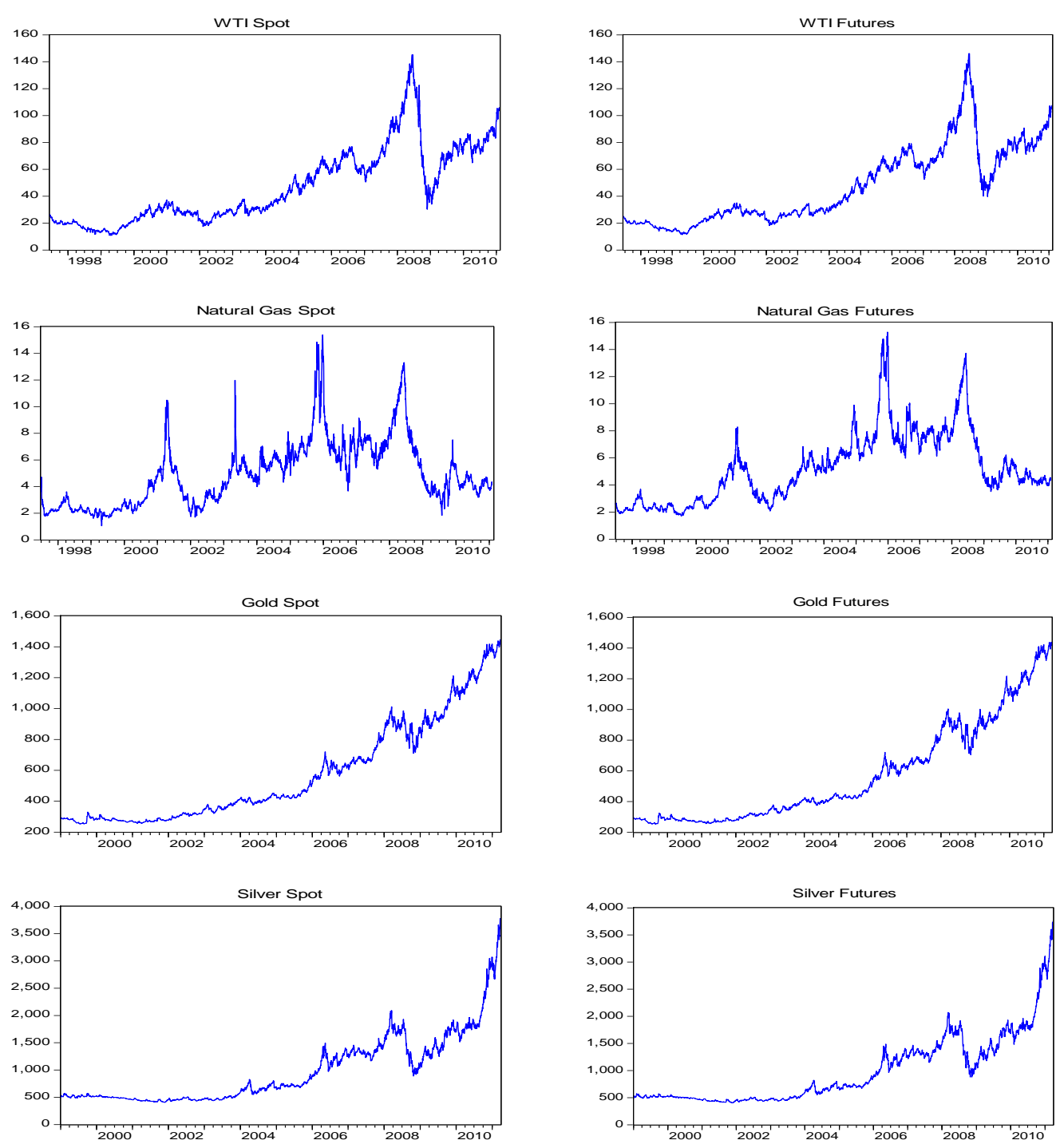

The time-variations of commodity spot and futures prices are displayed in Figure 1. We observe that commodity prices experienced a continuously increasing trend with some very large swings within the study period, although their patterns behave differently across the selected commodities. The crude oil prices attained their highest peak in 2008, while the two precious metals (i.e., gold and silver) reached their highest values in 2010. The natural gas price showed more volatility. Common price blips are observed in the mid-2008, and these blips may be explained by the serious effects of the recent global financial crisis. After a general fall over a short period, commodity prices increased sharply, particularly for the two precious metals. The differences in price patterns among the commodities can be explained by 
the fact that the natural gas price tends to be influenced in the short-run by short-lived factors (i.e., weather condition, changes in inventories and interruption in supply) due to the natural gas's regional characteristics, while the other commodities have a global coverage and suffer mainly from global economic and political events (i.e., economic downturn, production and consumption shocks, speculative attacks, regional conflicts, political tensions, etc.). Moreover, the 2007-2008 financial crisis may explain the large increases in gold and silver prices because it motivated global investors to implement a more defensive allocation strategy by investing in "refuge" or safe haven assets. Figure 2 presents the time evolution of the returns.

\section{Figure 2}

Time-variations in commodity spot and futures returns
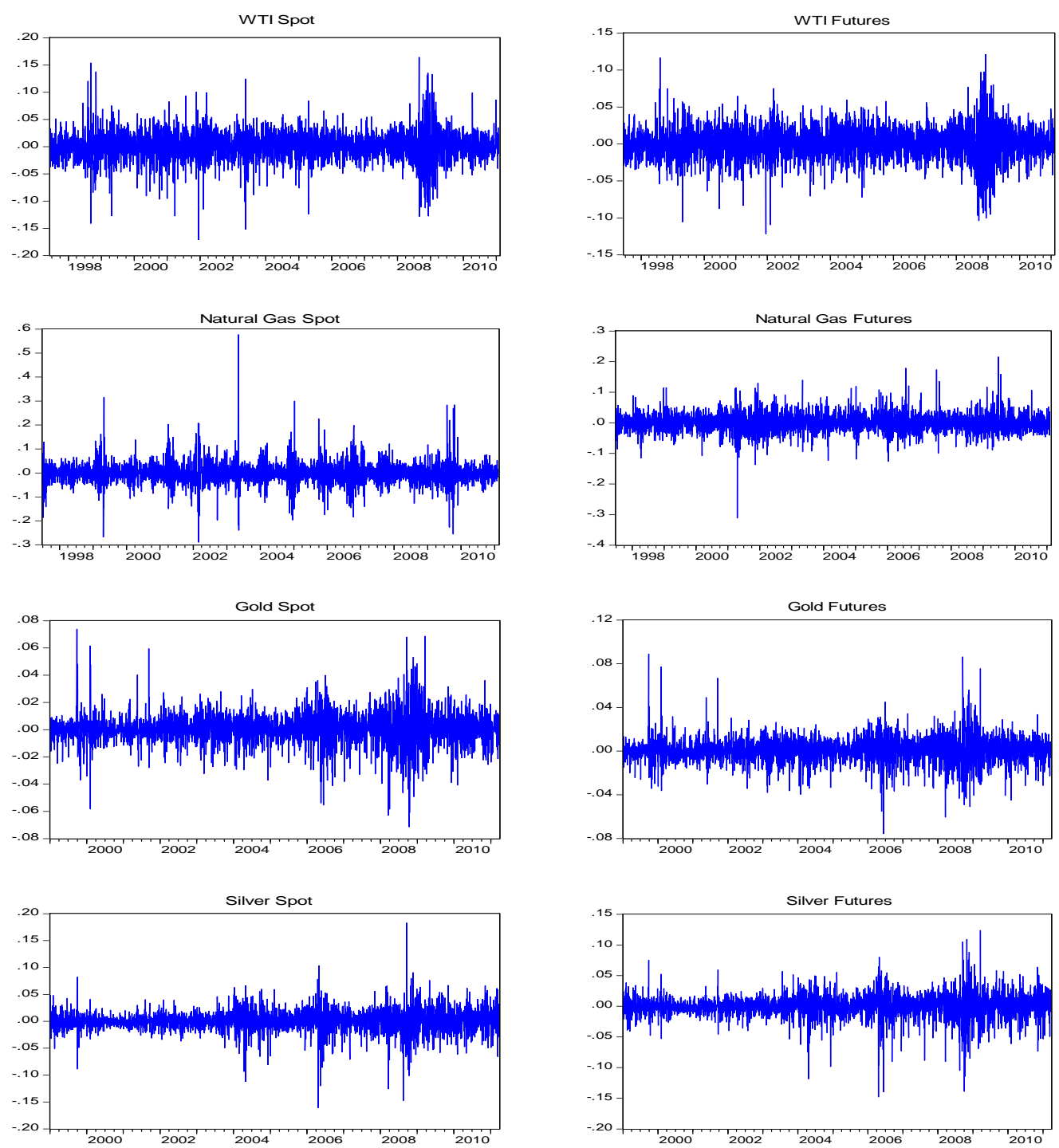

Table 2 reports the descriptive statistics for daily returns of the commodity spot and futures prices under consideration as well as their stochastic characteristics. Panel A of this table indicates that the daily average returns range from $0.016 \%$ (natural gas futures contracts) to $0.063 \%$ (spot silver and silver futures contracts) and are all positive over the whole study 
period. The spot and futures returns of natural gas have the highest unconditional volatility (standard deviations), followed respectively by that of crude oil returns, silver returns and gold returns. Natural gas has witnessed important advancement in extraction technology, resulting in the discovery of significant increases in reserves of shale gas and adding to volatility. Gold has a monetary value and its annual production is small relative to its available supply, giving rise to less historical volatility. Overall, gold represents the best investment in terms of realized Sharpe ratio among the four commodities over the sample period. Moreover, returns are negatively skewed for crude oil and silver, but positively skewed for natural gas and gold. Thus, these findings indicate that it is more likely to observe large negative returns for the former while large positive returns for the latter.

Table 2

Descriptive statistics and unit roots tests

\begin{tabular}{|c|c|c|c|c|c|c|c|c|}
\hline & \multicolumn{2}{|r|}{ Crude oil } & \multicolumn{2}{|c|}{ Natural gas } & \multicolumn{2}{|r|}{ Gold } & \multicolumn{2}{|r|}{ Silver } \\
\hline & Spot & Futures & Spot & Futures & Spot & Futures & Spot & Futures \\
\hline \multicolumn{9}{|c|}{ Panel A: Descriptive statistics } \\
\hline Mean (\%) & 0.039 & 0.041 & 0.035 & 0.016 & 0.050 & 0.050 & 0.063 & 0.063 \\
\hline Standard deviation & 2.619 & 2.313 & 4.549 & 3.029 & 1.128 & 1.150 & 1.975 & 1.900 \\
\hline Sharpe ratio & 0.015 & 0.018 & 0.008 & 0.005 & 0.044 & 0.043 & 0.032 & 0.033 \\
\hline Skewness & -0.151 & -0.186 & 0.828 & 0.077 & 0.070 & 0.187 & -0.422 & -0.779 \\
\hline Kurtosis & 4.530 & 2.701 & 13.117 & 5.968 & 5.315 & 6.054 & 8.045 & 7.481 \\
\hline JB & $3061.3^{* * *}$ & $1103.8^{* * *}$ & $25863^{* * *}$ & $5273.5^{* * *}$ & $3762.4^{* * *}$ & $4895.5^{* * *}$ & $8709.2^{* * *}$ & $7771.2^{* * *}$ \\
\hline$Q^{2}(10)$ & $734.06^{* * *}$ & $886.03^{* * *}$ & $609.62^{* * *}$ & $68.97^{* * *}$ & $543.75^{* * *}$ & $304.40^{* * *}$ & $295.55^{* * *}$ & $507.46^{* * *}$ \\
\hline $\mathrm{ARCH}(4)$ & $79.198^{* * *}$ & $80.112^{* * *}$ & $86.283^{* * *}$ & $8.516^{* * *}$ & $48.907^{* * *}$ & $36.273^{* * *}$ & $20.71^{* * *}$ & $39.805^{* * *}$ \\
\hline
\end{tabular}

Panel B: Unit root test statistics

\begin{tabular}{|c|c|c|c|c|c|c|c|c|}
\hline$\overline{\mathrm{ADF}}$ & $-34.58^{* * *}$ & $-34.23^{* * *}$ & $-37.18^{* * *}$ & $-34.26^{* * *}$ & $-32.01^{* * *}$ & $-32.49^{* * *}$ & $-33.55^{* * *}$ & $-32.21^{\prime}$ \\
\hline $\mathrm{KP}$ & & & & & 0.2 & 0.195 & 0 . & \\
\hline Zivot- & $-27.839^{*}$ & $34.523^{*}$ & $-26.633^{* *}$ & $-27.535^{*}$ & $-56.779^{* * *}$ & $-24.012^{* *}$ & $-60.999^{*}$ & $-57.173^{*}$ \\
\hline
\end{tabular}

Notes: This table reports the main descriptive statistics for returns and the results of several statistical tests applied to both returns and squared returns. $\mathrm{JB}, \mathrm{Q}^{2}(10)$ and $\mathrm{ARCH}(4)$ refer respectively to the empirical statistics of Jarque-Bera test for normality, Ljung-Box test for 10-order serial autocorrelation in squared returns, and Engle (1982)'s test for conditional heteroscedasticity. ADF and KPSS designate the empirical statistics of the Augmented Dickey-Fuller and Kwiatkowski-PhillipsSchmidt-Shin tests for the unit root and stationarity, respectively. The Zivot and Andrews (1992) unit root test examines the null of unit root hypothesis against the break-stationary alternative. ${ }^{* * *}$ indicates the rejection of the null hypotheses at the $1 \%$ level.

All return series have a leptokurtic behavior in view of significant excess kurtosis. The Jarque-Bera test confirms the departure from normality, while the Engle (1982) test for conditional heteroscedasticity and the Ljung-Box test show evidence of ARCH effects in returns and serial correlation of squared returns, respectively. Notice that the ARCH effects can be easily observed from Figure 2 where large (small) price changes tend to be followed by large (small) price changes over time.

We use the Augmented Dickey-Fuller (ADF) unit root test, the Kwiatkowski-PhilipsSchmidt-Shin (KPSS) stationarity test, and the Zivot and Andrews (1992) unit root test to examine the stationarity property of the commodity time series. The Zivot-Andrews test is robust to the presence of a potential structural break. The results from these tests (Panel B of 
Table 2) indicate that these commodity returns are stationary, and are thus appropriate for further analysis. Taken together, the stylized facts of the commodity returns reported in Table 2 clearly support our decision to adopt the GARCH methodology for modeling the conditional volatility of the commodity returns.

\section{Empirical results}

\subsection{Long memory (LM) tests}

The dual LM propriety in the conditional mean and variance of commodity returns and squared returns is investigated by employing two commonly-used tests in the existing literature: the log periodogram regression $(G P H)$ test (Geweke and Porter Hudak, 1983) and the Gaussian semi-parametric (GSP) test (Robinson, 1995). ${ }^{4}$

Table 3

Long memory test statistics

\begin{tabular}{|c|c|c|c|c|c|c|c|c|}
\hline & \multicolumn{2}{|c|}{ Crude oil } & \multicolumn{2}{|c|}{ Natural gas } & \multicolumn{2}{|r|}{ Gold } & \multicolumn{2}{|r|}{ Silver } \\
\hline & Spot & Future & Spot & Future & Spot & Future & Spot & Future \\
\hline \multicolumn{9}{|c|}{ GPH test applied to returns } \\
\hline \multirow[t]{2}{*}{$m=T^{0.5}$} & 0.093 & 0.110 & -0.163 & \begin{tabular}{l|l}
-0.099 \\
\end{tabular} & -0.103 & -0.088 & -0.330 & -0.041 \\
\hline & {$[0.315]$} & {$[0.235]$} & {$[0.077]$} & {$[0.282]$} & {$[0.287]$} & {$[0.356]$} & {$[0.732]$} & [0.671] \\
\hline \multirow[t]{2}{*}{$m=T^{0.6}$} & 0.034 & 0.043 & -0.113 & -0.004 & -0.108 & -0.107 & -0.012 & -0.015 \\
\hline & {$[0.567]$} & {$[0.434]$} & {$[0.055]$} & {$[0.943]$} & {$[0.075]$} & {$[0.080]$} & {$[0.848]$} & [0.806] \\
\hline \multicolumn{9}{|c|}{ GPH test applied to squared returns } \\
\hline \multirow{2}{*}{$m=T^{0.5}$} & 0.581 & 0.713 & 0.224 & 0.303 & 0.455 & 0.414 & 0.377 & 0.521 \\
\hline & {$[0.000]$} & {$[0.000]$} & {$[0.015]$} & {$[0.001]$} & {$[0.000]$} & {$[0.000]$} & {$[0.000]$} & {$[0.000]$} \\
\hline \multirow[t]{2}{*}{$m=T^{0.6}$} & 0.382 & 0.488 & 0.208 & 0.395 & 0.371 & 0.319 & 0.409 & 0.421 \\
\hline & {$[0.000]$} & {$[0.000]$} & {$[0.000]$} & {$[0.000]$} & {$[0.000]$} & {$[0.000]$} & {$[0.000]$} & {$[0.000]$} \\
\hline \multicolumn{9}{|c|}{ GSP test applied to returns } \\
\hline \multirow[t]{2}{*}{$m=T / 4$} & -0.019 & NA & -0.068 & 0.005 & 0.004 & -0.010 & 0.0001 & 0.007 \\
\hline & {$[0.210]$} & & {$[0.070]$} & {$[0.739]$} & {$[0.841]$} & {$[0.658]$} & [0.996] & {$[0.764]$} \\
\hline \multirow[t]{2}{*}{$m=T / 8$} & NA & 0.016 & -0.063 & -0.027 & -0.086 & -0.089 & -0.011 & -0.009 \\
\hline & & {$[0.621]$} & {$[0.067]$} & [0.244] & {$[0.072]$} & {$[0.061]$} & {$[0.819]$} & [0.849] \\
\hline \multicolumn{9}{|c|}{ GSP test applied to squared returns } \\
\hline \multirow{2}{*}{$m=T / 4$} & 0.223 & 0.241 & 0.256 & 0.131 & 0.221 & 0.195 & 0.159 & 0.193 \\
\hline & {$[0.000]$} & {$[0.000]$} & {$[0.000]$} & {$[0.000]$} & {$[0.000]$} & {$[0.000]$} & {$[0.000]$} & {$[0.000]$} \\
\hline \multirow[t]{2}{*}{$m=T / 8$} & 0.314 & 0.397 & 0.235 & 0.147 & 0.328 & 0.288 & 0.352 & 0.382 \\
\hline & {$[0.000]$} & {$[0.000]$} & {$[0.000]$} & {$[0.000]$} & {$[0.000]$} & {$[0.000]$} & {$[0.000]$} & {$[0.000]$} \\
\hline
\end{tabular}

Notes: $m$ denotes the bandwidth used for the GPH and the GPS tests. $T$ is the total number of observations. The associated $p$ values are reported in brackets.

Table 3 reports the results of these tests. Accordingly, we find very weak LM evidence for the returns series as both LM tests fail to reject the null hypothesis of no long-range dependence at the $5 \%$ level. For the squared returns, the two LM tests conclude favorably on the presence of the LM component at the $1 \%$ level. Past studies focusing on commodity markets

\footnotetext{
${ }^{4}$ As a preliminary check, we compute Lo's R/S statistics and find slight evidence of long memory for two return series (spot natural gas and spot silver), but strong evidence of long memory in squared returns for all four commodities. The results are not reported here, but can be made available under request to the corresponding author.
} 
also reach similar conclusions (e.g., Choi and Hammoudeh, 2009; Cheong, 2009; Aloui and Mabrouk, 2010; Mohammadi and Su, 2010; Wei et al., 2010). Overall, the results of the LM tests suggest the appropriateness of the GARCH models accommodating the long memory feature, as far as the modeling and forecasting of commodity return volatility are concerned.

\subsection{Estimates of GARCH-class models}

We now discuss the estimation results of the GARCH-class models for the four commodities. For each commodity return series, our conditional mean equation includes a constant and an autoregressive term, while its conditional variance is modeled by seven competing GARCH models taking the stylized empirical facts of asset returns (i.e., persistence, nonlinearity, asymmetry, and long memory) into account. These volatility models are estimated by using the Student- $t$ distributions and the Quasi-maximum Likelihood (QML) method. The use of the Student-t distributions is justified by the skewed and leptokurtic behavior of commodity returns (i.e., subsection 4.1). The parameter estimates are reported in Tables 4-7, together with the results of the diagnostic tests applied to standardized residuals.

For crude oil, Table 4 shows slight evidence of return predictability at the $10 \%$ level when the GARCH and IGARCH models are used to estimate the conditional volatility of the spot returns. With respect to the estimates of the conditional variances, we first observe that the stationarity condition is guaranteed since the sum of the ARCH and GARCH coefficients is less than one for all cases. These coefficients are also highly significant for all models as well as for both crude oil spot and futures returns. In particular, the value of the GARCH coefficients for the GARCH, IGARCH and EGARCH models is generally higher than 0.9, which thus indicates high persistence of volatility over time. When the LM property of return series is effectively accounted for within the frameworks of FIGARCH, FIAPARCH and HYGARCH, the value of the GARCH coefficients decreases substantially. The results for the EGARCH models show that the negative return shocks have significant and greater impact on conditional volatility than the positive return shocks of equal magnitude in view of the significance of the negative sign of the $\operatorname{EGARCH}(\delta)$ coefficient. The LM parameters, ranging from 0.281 (FIGARCH for spot returns) to 0.484 (HYGARCH for futures returns), are all significant at the $1 \%$ level for both the spot and futures returns, regardless of what nonlinear model (FIGARCH, FIAPARCH or HYGARCH) is used. More interestingly, the conditional volatility of crude oil spot and futures returns reacts asymmetrically to unexpected news as the $\operatorname{APARCH}(\gamma)$ parameter is positive and significant. Negative shocks thus have more impacts on volatility than positive shocks, which is entirely consistent with what we have learned 
from the EGARCH model. The $\operatorname{APARCH}(\delta)$ power term is also positive and significant at the conventional levels. The $\log (\mathrm{L}), \mathrm{AIC}$ and SIC criteria we use to rank the different GARCHtype models unanimously select the FIAPARCH as the best volatility model for both the crude oil spot and futures returns, suggesting the important role of the asymmetric effects and the LM component in the oil price volatility.

The results for natural gas presented in Table 5 are almost similar to those for crude oil. Indeed, the coefficients associated with the ARCH and GARCH terms are highly significant for both the spot and futures returns, regardless of the models used. The leverage parameter of the EGARCH model is negative and significant. The fractional difference or LM parameters $d$ are all significant at the $1 \%$ level for all cases, except for the HYGARCH model for futures returns where $d$ is only significant at the $10 \%$ level. These findings thus indicate a significant degree of long memory in the natural gas market. Compared to the results for crude oil, three main differences are however observed. First, there is no evidence of return predictability in view of insignificant AR(1) coefficients for all competing models. Second, the asymmetric volatility effects are not found for futures returns as the $\operatorname{APARCH}(\gamma)$ parameter is insignificant. Finally, the $\log (\mathrm{L})$, AIC and SIC criteria choose the FIAPARCH and standard GARCH models for spot and futures returns, respectively. ${ }^{5}$

The dynamic patterns followed by the gold conditional mean and variance are somewhat different from those of crude oil and natural gas (Table 6). We first find evidence of a significant return predictability for futures returns in case of the FIAPARCH model. While the coefficients associated with the GARCH terms continue to be highly significant, those associated with the ARCH terms are insignificant in five out of 14 cases. Moreover, the small size of the ARCH coefficients would indicate that the gold volatility does not change sharply over time. The EGARCH's leverage coefficient $(\delta)$ is significant but positive, implying that positive shocks have more impacts on conditional volatility than negative shocks. This result is fully supported by the findings from the FIAPARCH models where the $\operatorname{APARCH}(\gamma)$ parameters are negative and significant. According to the $\log (\mathrm{L})$, AIC and SIC criteria, the FIAPARCH is found to provide the best fit to the gold spot and futures return data.

\footnotetext{
${ }^{5}$ The fact that the GARCH model provides the best in-sample fit for natural gas futures returns seems to be contradictory with the LM tests, but is indeed consistent with the general consensus in the related literature according to which none of the commonly-used GARCH-type models can outperform the others in the in-sample estimations of commodity volatility. For example, Sadorsky (2006) shows that the GJR-GARCH fits well daily futures price volatility of natural gas. Kang et al. (2009) consider crude oil spot prices (Brent, Dubai, and WTI) and document that the CGARCH and FIGARCH models outperform the GARCH and IGARCH over the in-sample period. Wei et al. (2010) use both linear and nonlinear GARCH-type models, and find that none of them achieves a good degree of in-sample fit for both Brent and WTI return series.
} 
Table 4

Estimation results of GARCH-class models for crude oil

\begin{tabular}{|c|c|c|c|c|c|c|c|c|c|c|c|c|c|c|}
\hline & \multicolumn{7}{|c|}{ Spot returns } & \multicolumn{7}{|c|}{ Futures returns } \\
\hline & GARCH & IGARCH & RM & EGARCH & FIGARCH & FIAPARCH & HYGARCH & GARCH & IGARCH & RM & EGARCH & FIGARCH & FIAPARCH & HYGARCH \\
\hline Const (m) & $0.998^{* * *}$ & $0.986^{* * *}$ & $0.997^{* * *}$ & $0.974^{* * *}$ & $1.046^{* * * *}$ & $0.908^{* * *}$ & $1.055^{* * * 6}$ & $0.727^{* *}$ & $0.701^{\text {*** }}$ & $0.734^{* * *}$ & $0.732^{* * *}$ & $0.765^{* *}$ & $0.648^{*}$ & $0.781^{* * *}$ \\
\hline$\left(10^{-3}\right)$ & $(0.384)$ & $(0.385)$ & $(0.429)$ & $(0.439)$ & $(0.388)$ & $(0.384)$ & $(0.388)$ & $(0.329)$ & $(0.329)$ & $(0.367)$ & $(0.321)$ & $(0.332)$ & $(0.332)$ & $(0.332)$ \\
\hline $\mathrm{AR}(1)$ & $-0.028^{*}$ & $-0.028^{*}$ & -0.028 & -0.021 & -0.026 & $-0.029^{*}$ & -0.026 & -0.020 & -0.021 & -0.017 & -0.019 & -0.018 & -0.018 & -0.018 \\
\hline & $(0.017)$ & $(0.016)$ & $(0.018)$ & $(0.016)$ & $(0.017)$ & $(0.017)$ & $(0.017)$ & $(0.017)$ & $(0.017)$ & $(0.018)$ & $(0.018)$ & $(0.017)$ & $(0.017)$ & $(0.017)$ \\
\hline Const (v) & $0.106^{* * *}$ & $0.040^{* * * *}$ & & $0.169^{* * * *}$ & $0.536^{* *}$ & 0.435 & $0.632^{* * *}$ & $0.053^{* * * *}$ & $0.014^{* *}$ & & $0.131^{\text {**** }}$ & $0.202^{* *}$ & 3.997 & $0.291^{* * * *}$ \\
\hline & $(0.032)$ & $(0.015)$ & & $(0.033)$ & $(0.230)$ & $(0.522)$ & $(0.256)$ & $(0.019)$ & $(0.006)$ & & $(0.028)$ & $(0.083)$ & $(5.660)$ & $(0.104)$ \\
\hline $\mathrm{ARCH}$ & $0.045^{* * * *}$ & $0.053^{* * *}$ & 0.06 & $0.095^{* * * *}$ & $0.249^{* *}$ & $0.261^{* *}$ & $0.248^{* *}$ & $0.038^{* * *}$ & $0.042^{* * *}$ & 0.06 & $0.074^{* * *}$ & $0.315^{* * *}$ & $0.346^{* * * *}$ & $0.269^{* * *}$ \\
\hline & $(0.009)$ & $(0.009)$ & & $(0.014)$ & $(0.128)$ & $(0.115)$ & $(0.115)$ & $(0.007)$ & $(0.006)$ & & $(0.012)$ & $(0.059)$ & $(0.079)$ & $(0.061)$ \\
\hline GARCH & $0.938^{* * *}$ & $0.946^{* * * *}$ & 0.94 & $0.987^{* * * *}$ & $0.457^{* * *}$ & $0.501^{* * * *}$ & $0.499^{* * * *}$ & $0.949^{* * * *}$ & $0.958^{* * * *}$ & 0.94 & $0.925^{* * *}$ & $0.627^{* * *}$ & $0.696^{* * *}$ & $0.672^{* * * *}$ \\
\hline & $(0.012)$ & $(0.015)$ & & $(0.004)$ & $(0.141)$ & $(0.143)$ & $(0.139)$ & $(0.009)$ & $(0.034)$ & & $(0.011)$ & $(0.070)$ & $(0.066)$ & $(0.074)$ \\
\hline $\operatorname{EGARCH}(\delta)$ & & & & $\begin{array}{c}-0.042^{* * * *} \\
(0.009)\end{array}$ & & & & & & & $\begin{array}{c}-0.034 \\
(0.007))\end{array}$ & & & \\
\hline$d$ & & & & & $\begin{array}{c}0.281^{* * * *} \\
(0.052)\end{array}$ & $\begin{array}{c}0.318^{* * * *} \\
(0.073)\end{array}$ & $\begin{array}{c}0.351^{\text {**** }} \\
(0.086)\end{array}$ & & & & & $\begin{array}{c}0.358^{* * * *} \\
(0.065)\end{array}$ & $\begin{array}{c}0.417^{* * *} \\
(0.103)\end{array}$ & $\begin{array}{c}0.484^{\text {**** }} \\
(0.112)\end{array}$ \\
\hline $\operatorname{APARCH}(\gamma)$ & & & & & & $\begin{array}{l}0.307^{* *} \\
(0.140)\end{array}$ & & & & & & & $\begin{array}{l}0.337^{* * *} \\
(0.166)\end{array}$ & \\
\hline $\operatorname{APARCH}(\delta)$ & & & & & & $\begin{array}{l}1.508^{* * * *} \\
(0.291)\end{array}$ & & & & & & & $\begin{array}{l}1.330^{* * * *} \\
(0.334)\end{array}$ & \\
\hline Student- $d f$ & $\begin{array}{c}6.672^{* * * *} \\
(0.758)\end{array}$ & $\begin{array}{l}5.894^{* * *} \\
(0.650)\end{array}$ & $\begin{array}{l}7.484^{* * * *} \\
(0.729)\end{array}$ & $\begin{array}{c}6.764^{* * * *} \\
(0.652)\end{array}$ & $\begin{array}{c}6.845^{* * * *} \\
(0.818)\end{array}$ & $\begin{array}{c}6.949^{* * * *} \\
(0.822)\end{array}$ & $\begin{array}{c}6.898^{* * * *} \\
(0.821)\end{array}$ & $\begin{array}{l}9.547^{* * *} \\
(1.541)\end{array}$ & $\begin{array}{l}8.465^{* * *} \\
(1.296)\end{array}$ & $\begin{array}{c}10.095^{* * *} \\
(1.403)\end{array}$ & $\begin{array}{c}10.096^{* * *} \\
(1.393)\end{array}$ & $\begin{array}{c}9.634^{* * * *} \\
(1.553)\end{array}$ & $\begin{array}{c}10.251^{* * *} \\
(1.777)\end{array}$ & $\begin{array}{c}9.812^{* * * *} \\
(1.584)\end{array}$ \\
\hline$\underline{\log (\mathrm{L})}$ & 7523.6 & 7516.34 & 7501.69 & 7480.17 & 7520.51 & 7526.52 & 7520.82 & 8092.14 & 8086.95 & 8073.46 & 8039.82 & 8089.79 & 8096.23 & 8090.48 \\
\hline Diagnostic & & & & & & & & & & & & & & \\
\hline AIC & -4.623 & -4.619 & -4.612 & -4.595 & -4.621 & -4.623 & -4.620 & -4.973 & -4.970 & -4.963 & -4.939 & -4.971 & -4.974 & -4.971 \\
\hline SIC & -4.612 & -4.610 & -4.606 & -4.580 & -4.608 & -4.616 & -4.605 & -4.961 & -4.961 & -4.958 & -4.925 & -4.958 & -4.956 & -4.956 \\
\hline$\overline{\mathrm{ARCH}}(5)$ & $\begin{array}{l}1.276 \\
{[0.17]}\end{array}$ & $\begin{array}{l}1.057 \\
{[0.33]}\end{array}$ & $\begin{array}{l}1.449 \\
{[0.21]}\end{array}$ & $\begin{array}{c}1.951 \\
{[0.082]}\end{array}$ & $\begin{array}{l}1.112 \\
{[0.21]}\end{array}$ & $\begin{array}{l}1.154 \\
{[0.21]}\end{array}$ & $\begin{array}{c}1.138 \\
{[0.17]}\end{array}$ & $\begin{array}{l}1.021 \\
{[0.42]}\end{array}$ & $\begin{array}{l}1.026 \\
{[0.41]}\end{array}$ & $\begin{array}{c}1.762 \\
{[0.127]}\end{array}$ & $\begin{array}{c}2.008 \\
{[0.157}\end{array}$ & $\begin{array}{l}0.965 \\
{[0.50]}\end{array}$ & $\begin{array}{l}1.031 \\
{[0.42]}\end{array}$ & $\begin{array}{c}0.971 \\
{[0.49]}\end{array}$ \\
\hline$\overline{\mathrm{Q}^{2}(10)}$ & $\begin{array}{c}9.94 \\
{[0.35]}\end{array}$ & $\begin{array}{c}8.98 \\
{[044]}\end{array}$ & $\begin{array}{c}9.95 \\
{[0.34]}\end{array}$ & $\begin{array}{l}11.46 \\
{[0.25]}\end{array}$ & $\begin{array}{c}9.57 \\
{[0.38]}\end{array}$ & $\begin{array}{c}9.24 \\
{[0.42]}\end{array}$ & $\begin{array}{c}9.59 \\
{[0.38]}\end{array}$ & $\begin{array}{c}8.25 \\
{[0.51]}\end{array}$ & $\begin{array}{c}7.92 \\
{[0.54]}\end{array}$ & $\begin{array}{c}12.58 \\
{[0.127]}\end{array}$ & $\begin{array}{c}28.21 \\
{[0.058]}\end{array}$ & $\begin{array}{c}8.08 \\
{[0.52]}\end{array}$ & $\begin{array}{c}7.82 \\
{[0.55]}\end{array}$ & $\begin{array}{c}8.16 \\
{[0.52]}\end{array}$ \\
\hline$\overline{Q(10)}$ & $\begin{array}{c}9.69 \\
{[0.38]}\end{array}$ & $\begin{array}{l}8.705 \\
{[0.47]}\end{array}$ & $\begin{array}{c}7.742 \\
{[0.56]}\end{array}$ & $\begin{array}{l}10.937 \\
{[0.28]}\end{array}$ & $\begin{array}{l}8.916 \\
{[0.45]}\end{array}$ & $\begin{array}{l}8.547 \\
{[0.48]}\end{array}$ & $\begin{array}{l}8.983 \\
{[0.49]}\end{array}$ & $\begin{array}{l}6.806 \\
{[0.66]}\end{array}$ & $\begin{array}{l}6.773 \\
{[0.66]}\end{array}$ & $\begin{array}{l}6.854 \\
{[0.65]}\end{array}$ & $\begin{array}{c}7.491 \\
{[0.59]}\end{array}$ & $\begin{array}{l}6 . .824 \\
{[0.66]}\end{array}$ & $\begin{array}{c}6.797 \\
{[0.66]}\end{array}$ & $\begin{array}{c}6.952 \\
{[0.64]}\end{array}$ \\
\hline $\mathrm{JB}$ & $\begin{array}{c}820 \\
{[0.00]}\end{array}$ & $\begin{array}{c}849 \\
{[0.00]}\end{array}$ & $\begin{array}{c}946 \\
{[0.00]}\end{array}$ & $\begin{array}{c}896 \\
{[0.00]}\end{array}$ & $\begin{array}{c}819 \\
{[0.00]}\end{array}$ & $\begin{array}{c}823 \\
{[0.00]}\end{array}$ & $\begin{array}{c}790 \\
{[0.00]}\end{array}$ & $\begin{array}{c}313 \\
{[0.00]}\end{array}$ & $\begin{array}{c}324 \\
{[0.00]}\end{array}$ & $\begin{array}{c}225 \\
{[0.00]}\end{array}$ & $\begin{array}{c}199 \\
{[0.00]}\end{array}$ & $\begin{array}{c}207 \\
{[0.00]}\end{array}$ & $\begin{array}{c}176 \\
{[0.00]}\end{array}$ & $\begin{array}{c}193 \\
{[0.00]}\end{array}$ \\
\hline
\end{tabular}

Notes: The table reports the estimation results of GARCH-class models for crude oil spot and futures returns. We consider seven competing models: standard GARCH, IGARCH, RiskMetrics (RM), EGARCH, FIGARCH, FIAPARCH, and HYGARCH. Const $(\mathrm{m})$ and Const (v) refer to the constant terms in mean and variance equations. Standard errors of estimates are reported in parentheses. $\mathrm{Q}^{2}(10)$ and $\mathrm{ARCH}(5)$ are the empirical statistics of the Ljung-Box test for autocorrelation with 10 lags applied to squared standardized residuals and the Engle (1982) test for conditional heteroscedasticity applied to standardized residuals, respectively. The $p$-values associated with the statistical tests are presented in brackets. *, ${ }^{* *}$ and ${ }^{* * * *}$ represent the significance at the $10 \%, 5 \%$ and $1 \%$ levels, respectively. 
Table 5

Estimation results of GARCH-class models for natural gas

\begin{tabular}{|c|c|c|c|c|c|c|c|c|c|c|c|c|c|c|}
\hline & \multicolumn{7}{|c|}{ Spot returns } & \multicolumn{7}{|c|}{ Futures returns } \\
\hline & GARCH & IGARCH & RM & EGARCH & FIGARCH & FIAPARCH & HYGARCH & GARCH & IGARCH & RM & EGARCH & FIGARCH & FIAPARCH & HYGARCH \\
\hline Const (m) & 0.266 & 0.296 & 0.301 & 0.278 & 0.290 & 0.232 & 0.245 & 0.309 & 0.355 & 0.408 & 0.249 & 0.275 & 0.257 & 0.274 \\
\hline$\left(10^{-3}\right)$ & $(0.571)$ & $(0.567)$ & $(0.671)$ & $(0.552)$ & $(0.568)$ & $(0.584)$ & $(0.571)$ & $(0.461)$ & $(0.461)$ & $(0.521)$ & $(0.426)$ & $(0.462)$ & $(0.468)$ & $(0.463)$ \\
\hline $\mathrm{AR}(1)$ & 0.013 & 0.013 & 0.013 & 0.013 & 0.012 & 0.013 & 0.013 & -0.013 & -0.012 & -0.012 & -0.015 & -0.013 & -0.014 & -0.013 \\
\hline & $(0.018)$ & $(0.017)$ & $(0.019)$ & $(0.018)$ & $(0.018)$ & $(0.017)$ & $(0.018)$ & $(0.016)$ & $(0.015)$ & $(0.017)$ & $(0.017)$ & $(0.016)$ & $(0.016)$ & $(0.016)$ \\
\hline Const (v) & $0.657^{* * *}$ & $0.480^{* * * *}$ & & $0.419^{* * *}$ & $0.454^{* * *}$ & $0.435^{* *}$ & $0.545^{* * * *}$ & $0.197^{* * * *}$ & $0.071^{* *}$ & & $0.203^{* * * *}$ & $0.779^{*}$ & $0.786^{*}$ & $0.899^{* * *}$ \\
\hline & $(0.148)$ & (0.109) & & $(0.051)$ & $(0.105)$ & $(0.222)$ & $(0.122)$ & $(0.056)$ & $(0.028)$ & & $(0.051)$ & $(0.497)$ & $(0.488)$ & $(0.481)$ \\
\hline $\mathrm{ARCH}$ & $0.145^{* * *}$ & $0.170^{* * * *}$ & 0.06 & 0.252 & $0.249^{* * *}$ & $0.261^{* *}$ & $0.248^{* *}$ & $0.041^{* * * *}$ & $0.051^{* * * *}$ & 0.06 & $0.098^{* * * *}$ & $0.249^{* * *}$ & $0.254^{* * *}$ & $0.241^{* * * *}$ \\
\hline & $(0.017)$ & $(0.018)$ & & $(0.022)$ & $(0.128)$ & $(0.115)$ & $(0.115)$ & $(0.008)$ & $(0.011)$ & & $(0.016)$ & $(0.108)$ & $(0.103)$ & $(0.075)$ \\
\hline GARCH & $0.825^{* * * *}$ & $0.830^{* * * *}$ & 0.94 & $0.895^{*}$ & $0.457^{* * * *}$ & $0.501^{* * * *}$ & $0.499^{* * * *}$ & $0.937^{* * *}$ & $0.948^{* * * *}$ & 0.94 & $0.941^{* * *}$ & $0.525^{* * * *}$ & $0.528^{* * * *}$ & $0.568^{* * * *}$ \\
\hline & $(0.019)$ & $(0.006)$ & & $(0.014)$ & $(0.141)$ & $(0.143)$ & $(0.139)$ & $(0.011)$ & $(0.017)$ & & $(0.006)$ & $(0.174)$ & $(0.144)$ & $(0.202)$ \\
\hline EGARCH $(\delta)$ & & & & $\begin{array}{c}-0.076^{* * * *} \\
(0.017)\end{array}$ & & & & & & & $\begin{array}{c}-0.021^{* * * *} \\
(0.008)\end{array}$ & & & \\
\hline$d$ & & & & & $\begin{array}{c}0.281^{* * * *} \\
(0.052)\end{array}$ & $\begin{array}{c}0.318^{* * *} \\
(0.073)\end{array}$ & $\begin{array}{c}0.351^{\text {**** }} \\
(0.086)\end{array}$ & & & & & $\begin{array}{c}0.289^{* * * *} \\
(0.094)\end{array}$ & $\begin{array}{c}0.288^{* * * *} \\
(0.066)\end{array}$ & $\begin{array}{c}0.365^{*} \\
(0.214)\end{array}$ \\
\hline $\operatorname{APARCH}(\gamma)$ & & & & & & $\begin{array}{l}0.307^{* * *} \\
(0.140)\end{array}$ & & & & & & & $\begin{array}{c}-0.032 \\
(0.108)\end{array}$ & \\
\hline $\operatorname{APARCH}(\delta)$ & & & & & & $\begin{array}{l}1.508^{* * * *} \\
(0.291)\end{array}$ & & & & & & & $\begin{array}{l}1.858^{* * * *} \\
(0.144)\end{array}$ & \\
\hline Student- $d f$ & $\begin{array}{c}6.354^{* * *} \\
(0.823)\end{array}$ & $\begin{array}{l}5.792^{* * * *} \\
(0.706)\end{array}$ & $\begin{array}{l}6.864^{* * *} \\
(0.685)\end{array}$ & $\begin{array}{l}5.648^{* * *} \\
(0.251)\end{array}$ & $\begin{array}{l}5.755^{\text {**** }} \\
(0.717)\end{array}$ & $\begin{array}{l}6.356^{* * * *} \\
(0.821)\end{array}$ & $\begin{array}{c}6.368^{* * * *} \\
(0.821)\end{array}$ & $\begin{array}{l}5.551^{* * *} \\
(0.535)\end{array}$ & $\begin{array}{l}4.812^{* * *} \\
(0.437)\end{array}$ & $\begin{array}{l}6.291^{* * *} \\
(0.495)\end{array}$ & $\begin{array}{c}5.874^{* * * *} \\
(0.539)\end{array}$ & $\begin{array}{l}5.446^{* * *} \\
(0.528)\end{array}$ & $\begin{array}{c}5.743^{* * * *} \\
(0.539)\end{array}$ & $\begin{array}{c}5.472^{* * * *} \\
(0.528)\end{array}$ \\
\hline $\log (\mathrm{L})$ & 5998.05 & 5994.08 & 5925.13 & 5968.69 & 5994.16 & 6001.86 & 5998.70 & 6918.33 & 6910.06 & 6891.92 & 6911.91 & 6916.36 & 6916.91 & 6916.48 \\
\hline \multicolumn{15}{|c|}{ Diagnostic tests } \\
\hline AIC & -3.699 & -3.698 & -3.657 & -3.681 & -3.697 & -3.700 & -3.699 & -4.268 & -4.264 & -4.254 & -4.267 & -4.266 & -4.265 & -4.266 \\
\hline SIC & -3.688 & -3.688 & -3.651 & -3.668 & -3.684 & -3.689 & -3.684 & -4.257 & -4.254 & -4.248 & -4.251 & -4.253 & -4.248 & -4.251 \\
\hline ARCH(5) & $\begin{array}{l}0.138 \\
{[0.98]}\end{array}$ & $\begin{array}{l}0.131 \\
{[0.98]}\end{array}$ & $\begin{array}{c}0.784 \\
{[0.561]}\end{array}$ & $\begin{array}{c}0.550 \\
{[0.738]}\end{array}$ & $\begin{array}{l}0.137 \\
{[0.98]}\end{array}$ & $\begin{array}{l}0.161 \\
{[0.98]}\end{array}$ & $\begin{array}{l}0.112 \\
{[0.98]}\end{array}$ & $\begin{array}{l}0.528 \\
{[0.75]}\end{array}$ & $\begin{array}{l}0.557 \\
{[0.73]}\end{array}$ & $\begin{array}{l}0.862 \\
{[0.50]}\end{array}$ & $\begin{array}{c}0.569 \\
{[0.723]}\end{array}$ & $\begin{array}{l}0.710 \\
{[0.62]}\end{array}$ & $\begin{array}{l}0.708 \\
{[0.62]}\end{array}$ & $\begin{array}{l}0.803 \\
{[0.55]}\end{array}$ \\
\hline$\overline{\mathrm{Q}^{2}(10)}$ & $\begin{array}{l}1.895 \\
{[0.98]}\end{array}$ & $\begin{array}{l}2.474 \\
{[0.96]}\end{array}$ & $\begin{array}{c}5.078 \\
{[0.749]}\end{array}$ & $\begin{array}{l}4.204 \\
{[0.84]}\end{array}$ & $\begin{array}{l}2.513 \\
{[0.96]}\end{array}$ & $\begin{array}{l}2.260 \\
{[0.97]}\end{array}$ & $\begin{array}{c}1.892 \\
{[0.98]}\end{array}$ & $\begin{array}{l}9.149 \\
{[0.33]}\end{array}$ & $\begin{array}{l}8.694 \\
{[0.37]}\end{array}$ & $\begin{array}{c}10.302 \\
{[0.244]}\end{array}$ & $\begin{array}{c}9.154 \\
{[0.329]}\end{array}$ & $\begin{array}{l}9.648 \\
{[0.29]}\end{array}$ & $\begin{array}{l}9.831 \\
{[0.27]}\end{array}$ & $\begin{array}{l}10.37 \\
{[0.24]}\end{array}$ \\
\hline $\mathrm{Q}(10)$ & $\begin{array}{l}36.688 \\
{[0.00]}\end{array}$ & $\begin{array}{c}33.148 \\
{[0.00]}\end{array}$ & $\begin{array}{c}40.836 \\
{[0.00]}\end{array}$ & $\begin{array}{l}46.435 \\
{[0.00]}\end{array}$ & $\begin{array}{l}35.713 \\
{[0.00]}\end{array}$ & $\begin{array}{l}35.275 \\
{[0.00]}\end{array}$ & $\begin{array}{l}33.840 \\
{[0.00]}\end{array}$ & $\begin{array}{l}8.196 \\
{[0.51]}\end{array}$ & $\begin{array}{l}8.221 \\
{[0.51]}\end{array}$ & $\begin{array}{l}8.327 \\
{[0.50]}\end{array}$ & $\begin{array}{l}9.428 \\
{[0.40]}\end{array}$ & $\begin{array}{l}7.831 \\
{[0.55]}\end{array}$ & $\begin{array}{l}8.120 \\
{[0.52]}\end{array}$ & $\begin{array}{l}8.361 \\
{[0.49]}\end{array}$ \\
\hline$\overline{\mathrm{JB}}$ & $\begin{array}{l}21572 \\
{[0.00]}\end{array}$ & $\begin{array}{l}18497 \\
{[0.00]}\end{array}$ & $\begin{array}{l}11917 \\
{[0.00]}\end{array}$ & $\begin{array}{l}22185 \\
{[0.00]}\end{array}$ & $\begin{array}{l}18775 \\
{[0.00]}\end{array}$ & $\begin{array}{l}19927 \\
{[0.00]}\end{array}$ & $\begin{array}{l}17762 \\
{[0.00]}\end{array}$ & $\begin{array}{c}1463 \\
{[0.00]}\end{array}$ & $\begin{array}{c}1582 \\
{[0.00]}\end{array}$ & $\begin{array}{c}1106 \\
{[0.00]}\end{array}$ & $\begin{array}{c}2466 \\
{[0.00]}\end{array}$ & $\begin{array}{c}1177 \\
{[0.00]}\end{array}$ & $\begin{array}{c}1373 \\
{[0.00]}\end{array}$ & $\begin{array}{c}1679 \\
{[0.00]}\end{array}$ \\
\hline
\end{tabular}

Notes: The table reports the estimation results of GARCH-class models for natural gas spot and futures returns. We consider seven competing models: standard GARCH, IGARCH, RiskMetrics (RM), EGARCH, FIGARCH, FIAPARCH, and HYGARCH. Const $(\mathrm{m})$ and Const (v) refer to the constant terms in mean and variance equations. Standard errors of estimates are reported in parentheses. $\mathrm{Q}^{2}(10)$ and $\mathrm{ARCH}(5)$ are the empirical statistics of the Ljung-Box test for autocorrelation with 10 lags applied to squared standardized residuals and the Engle (1982) test for conditional heteroscedasticity applied to standardized residuals, respectively. The p-values associated with the statistical tests are presented in brackets. ${ }^{* * *}$ and ${ }^{* * *}$ denote the significance at the $10 \%$, $5 \%$ and $1 \%$ levels, respectively. 
Table 6

Estimation results of GARCH-class models for gold

\begin{tabular}{|c|c|c|c|c|c|c|c|c|c|c|c|c|c|c|}
\hline & \multicolumn{7}{|c|}{ Spot returns } & \multicolumn{7}{|c|}{ Futures returns } \\
\hline & GARCH & IGARCH & RM & EGARCH & FIGARCH & FIAPARCH & HYGARCH & GARCH & IGARCH & RM & EGARCH & FIGARCH & FIAPARCH & HYGARCH \\
\hline$\overline{\text { Const (m) }}$ & $0.417^{\text {**** }}$ & $0.419^{\text {**** }}$ & $0.378^{* *}$ & $0.431^{* * * *}$ & $0.419^{* * *}$ & $0.473^{\text {**** }}$ & $0.417^{* * * *}$ & $0.477^{* * *}$ & $0.476^{* * *}$ & $0.447^{* * 3}$ & $0.424^{* * * *}$ & $0.474^{* * * *}$ & $0.546^{* * *}$ & $0.475^{* * *}$ \\
\hline$\left(10^{-3}\right)$ & $(0.140)$ & $(0.139)$ & $(0.152)$ & $(0.131)$ & $(0.139)$ & $(0.140)$ & $(0.140)$ & $(0.150)$ & $(0.148)$ & $(0.161)$ & $(0.143)$ & $(0.149)$ & $(0.147)$ & $(0.150)$ \\
\hline $\mathrm{AR}(1)$ & -0.027 & -0.027 & -0.024 & -0.023 & -0.026 & -0.025 & -0.027 & -0.023 & -0.023 & -0.021 & -0.025 & -0.022 & $-0.027^{* *}$ & -0.023 \\
\hline & $(0.017)$ & $(0.017)$ & $(0.018)$ & $(0.016)$ & $(0.017)$ & $(0.018)$ & $(0.017)$ & $(0.016)$ & $(0.016)$ & $(0.017)$ & $(0.016)$ & $(0.017)$ & $(0.016)$ & $(0.016)$ \\
\hline Const (v) & $0.083^{* *}$ & $0.087^{* * * *}$ & & $0.129^{* * * *}$ & $0.093^{* * *}$ & 0.311 & $0.088^{* * *}$ & $0.084^{* * *}$ & $0.079^{* * *}$ & & $0.114^{* * * *}$ & $0.669^{* * *}$ & 0.443 & 0.082 \\
\hline & $(0.036)$ & $(0.031)$ & & $(0.023)$ & $(0.042)$ & $(0.269)$ & $(0.046)$ & $(0.043)$ & $(0.033)$ & & $(0.023)$ & $(0.227)$ & $(0.333)$ & $(0.064)$ \\
\hline $\mathrm{ARCH}$ & $0.061^{* * *}$ & $0.060^{* * * *}$ & 006 & $0.099^{* * * *}$ & 0.028 & -0.002 & 0.029 & $0.050^{* * *}$ & $0.051^{* * * *}$ & 006 & $0.085^{* * * *}$ & $0.320^{* * * *}$ & -0.046 & -0.017 \\
\hline & $(0.010)$ & $(0.009)$ & 0.00 & $(0.013)$ & $(0.068)$ & $(0.044)$ & $(0.070)$ & $(0.009)$ & $(0.009)$ & 0.00 & $(0.012)$ & $(0.052)$ & $(0.038)$ & $(0.071)$ \\
\hline GARCH & $0.939^{* * * *}$ & $0.939^{* * *}$ & (94 & $0.943^{* * *}$ & $0.934^{* * * *}$ & $0.952^{* * *}$ & $0.934^{* * *}$ & $0.948^{* * * *}$ & $0.949^{* * *}$ & 0.94 & $0.994^{* * *}$ & $0.672^{* * *}$ & $0.959^{* * *}$ & $0.950^{* * * *}$ \\
\hline & $(0.009)$ & $(0.011)$ & 0.94 & $(0.002)$ & $(0.022)$ & $(0.015)$ & $(0.023)$ & $(0.009)$ & $(0.008)$ & 0.94 & $(0.002)$ & $(0.062)$ & $(0.011)$ & $(0.027)$ \\
\hline $\operatorname{EGARCH}(\delta)$ & & & & $\begin{array}{c}0.058^{* * *} \\
(0.009)\end{array}$ & & & & & & & $\begin{array}{c}0.049^{* * * *} \\
(0.009)\end{array}$ & & & \\
\hline$d$ & & & & & $0.479^{* * * *}$ & $0.544^{* * * *}$ & $0.486^{* * *}$ & & & & & $0.391^{* * *}$ & $0.432^{* * *}$ & $0.446^{* * *}$ \\
\hline & & & & & $(0.104)$ & $(0.174)$ & $(0.041)$ & & & & & $(0.053)$ & $(0.076)$ & $(0.003)$ \\
\hline $\operatorname{APARCH}(\gamma)$ & & & & & & $\begin{array}{c}-0.694^{* * *} \\
(0.236)\end{array}$ & & & & & & & $\begin{array}{c}-0.699^{* * * *} \\
(0.197)\end{array}$ & \\
\hline $\operatorname{APARCH}(\delta)$ & & & & & & $1.255^{\text {***** }}$ & & & & & & & 1.185 & \\
\hline & & & & & & $(0.173)$ & & & & & & & $(0.136)$ & \\
\hline Student- $d f$ & $3.791^{\text {*a* }}$ & $3.841^{* * * *}$ & $4.610^{* * * *}$ & $4.253^{* * *}$ & $3.845^{* *}$ & $4.340^{* * * *}$ & $3.793^{* * *}$ & $3.960^{* * * *}$ & $3.922^{* * *}$ & $4.680^{* * * *}$ & $4.203^{* * *}$ & $3.917^{* * *}$ & $4.376^{* * * *}$ & $3.955^{* * *}$ \\
\hline $\log (\mathrm{L})$ & $\begin{array}{r}(0.304) \\
9329.91\end{array}$ & $\begin{array}{l}(0.260) \\
9329.88\end{array}$ & $\begin{array}{l}(0.271) \\
9316.63\end{array}$ & $\begin{array}{l}(0.353) \\
9268.98\end{array}$ & $\begin{array}{r}(0.260) \\
9329.99\end{array}$ & $\begin{array}{l}(0 . \\
934\end{array}$ & $\begin{array}{l}(0 \\
93\end{array}$ & $\begin{array}{l}(0 \\
91\end{array}$ & $\begin{array}{l}(0 . \\
917\end{array}$ & $\begin{array}{l}(0.287) \\
016191\end{array}$ & $\begin{array}{l}(0 . \\
911\end{array}$ & & $\begin{array}{l}(0.373) \\
\mathbf{9 1 9 3 6 7}\end{array}$ & \\
\hline Diagnostict & & & & & & & & & & & & & & \\
\hline AIC & -6.470 & -6.471 & -6.463 & -6.427 & -6.470 & -6.482 & -6.469 & -6.363 & -6.364 & -6.356 & -6.319 & -6.363 & -6.374 & -6.362 \\
\hline$\overline{\text { SIC }}$ & -6.458 & -6.461 & -6.457 & -6.410 & -6.455 & -6.463 & -6.452 & -6.351 & -6.354 & -6.350 & -6.303 & -6.348 & -6.355 & -6.345 \\
\hline$\overline{\mathrm{ARCH}}(5)$ & $\begin{array}{l}1.320 \\
{[0.15]}\end{array}$ & $\begin{array}{l}1.320 \\
{[0.15]}\end{array}$ & $\begin{array}{c}2.159 \\
{[0.056]}\end{array}$ & $\begin{array}{c}1.681 \\
{[0.148]}\end{array}$ & $\begin{array}{c}1.281 \\
{[0.16]}\end{array}$ & $\begin{array}{c}1.507 \\
{[0.01]}\end{array}$ & $\begin{array}{c}1.281 \\
{[0.16]}\end{array}$ & $\begin{array}{c}1.762 \\
{[0.12]}\end{array}$ & $\begin{array}{c}1.82 \\
{[0.11]}\end{array}$ & $\begin{array}{c}0.693 \\
{[0.628]}\end{array}$ & $\begin{array}{c}0.902 \\
{[0.478]}\end{array}$ & $\begin{array}{c}1.177 \\
{[0.26]}\end{array}$ & $\begin{array}{c}1.254 \\
{[0.11]}\end{array}$ & $\begin{array}{c}1.155 \\
{[0.28]}\end{array}$ \\
\hline$\overline{\mathrm{Q}^{2}(10)}$ & $\begin{array}{l}15.02 \\
{[0.09]}\end{array}$ & $\begin{array}{l}14.98 \\
0.09]\end{array}$ & $\begin{array}{l}13.12 \\
{[0.11]}\end{array}$ & $\begin{array}{c}9.701 \\
{[0.287]}\end{array}$ & $\begin{array}{c}14.85 \\
{[0.09]}\end{array}$ & $\begin{array}{c}12.15 \\
{[0.20]}\end{array}$ & $\begin{array}{c}14.8 \\
{[0.09]}\end{array}$ & $\begin{array}{l}11.10 \\
{[0.19]}\end{array}$ & $\begin{array}{c}11.20 \\
{[0.19]}\end{array}$ & $\begin{array}{c}5.197 \\
{[0.736]}\end{array}$ & $\begin{array}{c}5.941 \\
{[0.654]}\end{array}$ & $\begin{array}{c}13.7 \\
{[0.09]}\end{array}$ & $\begin{array}{c}17.4 \\
{[0.04]}\end{array}$ & $\begin{array}{c}13.6 \\
{[0.09]}\end{array}$ \\
\hline$\overline{\mathrm{Q}(10)}$ & $\begin{array}{l}13.136 \\
{[0.16]}\end{array}$ & $\begin{array}{l}13.136 \\
{[0.16]}\end{array}$ & $\begin{array}{l}11.976 \\
{[0.21]}\end{array}$ & $\begin{array}{l}13.066 \\
{[0.16]}\end{array}$ & $\begin{array}{l}13.993 \\
{[0.12]}\end{array}$ & $\begin{array}{c}10.983 \\
{[0.28]}\end{array}$ & $\begin{array}{c}13.518 \\
{[0.14]}\end{array}$ & $\begin{array}{l}14.032 \\
{[0.12]}\end{array}$ & $\begin{array}{l}14.235 \\
{[0.11]}\end{array}$ & $\begin{array}{c}12.164 \\
{[0.20]}\end{array}$ & $\begin{array}{l}17.252 \\
{[0.05]}\end{array}$ & $\begin{array}{l}14.287 \\
{[0.11]}\end{array}$ & $\begin{array}{l}13.511 \\
{[0.14]}\end{array}$ & $\begin{array}{l}14.328 \\
{[0.11]}\end{array}$ \\
\hline$\overline{\mathrm{JB}}$ & $\begin{array}{c}2798 \\
{[0.00]}\end{array}$ & $\begin{array}{c}2803 \\
{[0.00]}\end{array}$ & $\begin{array}{c}4018 \\
{[0.00]}\end{array}$ & $\begin{array}{c}2072 \\
{[0.00]}\end{array}$ & $\begin{array}{c}3926 \\
{[0.00]}\end{array}$ & $\begin{array}{c}3763 \\
{[0.00]}\end{array}$ & $\begin{array}{c}4125 \\
{[0.00]}\end{array}$ & $\begin{array}{c}6919 \\
{[0.00]}\end{array}$ & $\begin{array}{c}6572 \\
{[0.00]}\end{array}$ & $\begin{array}{c}9944 \\
{[0.00]}\end{array}$ & $\begin{array}{c}7581 \\
{[0.00]}\end{array}$ & $\begin{array}{c}7744 \\
{[0.00]}\end{array}$ & $\begin{array}{c}7928 \\
{[0.00]}\end{array}$ & $\begin{array}{c}7412 \\
{[0.00]}\end{array}$ \\
\hline
\end{tabular}

Notes: This table reports the estimation results of GARCH-class models for natural gas spot and futures returns. We consider seven competing models: standard GARCH, IGARCH, RiskMetrics (RM), EGARCH, FIGARCH, FIAPARCH, and HYGARCH. Const (m) and Const (v) refer to the constant terms in mean and variance equations. Standard errors of estimates are reported in parentheses. $\mathrm{Q}^{2}(10)$ and $\mathrm{ARCH}(5)$ are the empirical statistics of the Ljung-Box test for autocorrelation with 10 lags applied to squared standardized residuals and the Engle (1982) test for conditional heteroscedasticity applied to standardized residuals, respectively. The $p$-values associated with the statistical tests are presented in brackets. ${ }^{* * *}$ and ${ }^{* * *}$ denote the significance at the $10 \%$, $5 \%$ and $1 \%$ levels, respectively. 
Table 7

Estimation results of GARCH-class models for silver

\begin{tabular}{|c|c|c|c|c|c|c|c|c|c|c|c|c|c|c|}
\hline & \multicolumn{7}{|c|}{ Spot returns } & \multicolumn{7}{|c|}{ Futures returns } \\
\hline & GARCH & IGARCH & RM & EGARCH & FIGARCH & FIAPARCH & HYGARCH & GARCH & IGARCH & RM & EGARCH & FIGARCH & FIAPARCH & HYGARCH \\
\hline Const (m) & 0.224 & 0.226 & 0.184 & $0.259^{* * *}$ & 0.241 & $0.347^{*}$ & 0.239 & $0.629^{* * * *}$ & $0.720^{* * * *}$ & $0.559^{* * *}$ & $0.692^{\text {**** }}$ & $0.634^{* * * *}$ & $0.716^{* * * *}$ & $0.635^{\text {**** }}$ \\
\hline$\left(10^{-3}\right)$ & $(0.208)$ & $(0.207)$ & $(0.228)$ & $(0.112)$ & $(0.206)$ & $(0.206)$ & $(0.207)$ & $(0.221)$ & $(0.219)$ & $(0.243)$ & $(0.213)$ & $(0.219)$ & $(0.220)$ & $(0.220)$ \\
\hline $\operatorname{AR}(1)$ & $\begin{array}{c}-0.089^{* * * *} \\
(0.018)\end{array}$ & $\begin{array}{c}-0.089^{* * * *} \\
(0.018)\end{array}$ & $\begin{array}{c}-0.088^{* * * *} \\
(0.019)\end{array}$ & $\begin{array}{c}-0.094^{* * * *} \\
(0.016)\end{array}$ & $\begin{array}{c}-0.094^{* * * *} \\
(0.018)\end{array}$ & $\begin{array}{c}-0.099^{* * * *} \\
(0.018)\end{array}$ & $\begin{array}{c}-0.095^{* * *} \\
(0.018)\end{array}$ & $\begin{array}{l}-0.029^{*} \\
(0.018)\end{array}$ & $\begin{array}{l}-0.029^{*} \\
(0.017)\end{array}$ & $\begin{array}{l}-0.027 \\
(0.018)\end{array}$ & $\begin{array}{l}-0.023^{*} \\
(0.015)\end{array}$ & $\begin{array}{l}-0.034^{*} \\
(0.018)\end{array}$ & $\begin{array}{l}-0.035^{*} \\
(0.018)\end{array}$ & $\begin{array}{c}-0.034^{\text {*** }} \\
(0.018)\end{array}$ \\
\hline Const (v) & $\begin{array}{l}0.097^{* *} \\
(0.051)\end{array}$ & $\begin{array}{l}0.010^{* * *} \\
(0.004)\end{array}$ & & $\begin{array}{c}0.113^{* * *} \\
(0.018)\end{array}$ & $\begin{array}{l}0.071^{* *} \\
(0.051)\end{array}$ & $\begin{array}{c}0.035 \\
(0.042)\end{array}$ & $\begin{array}{l}0.068^{* * *} \\
(0.052)\end{array}$ & $\begin{array}{l}0.088^{* * *} \\
(0.039)\end{array}$ & $\begin{array}{l}0.085^{* * *} \\
(0.034)\end{array}$ & & $\begin{array}{l}0.109^{* * * *} \\
(0.020)\end{array}$ & $\begin{array}{l}0.078^{* * *} \\
(0.037)\end{array}$ & $\begin{array}{c}0.023 \\
(0.025)\end{array}$ & $\begin{array}{l}0.083^{* * *} \\
(0.042)\end{array}$ \\
\hline $\mathrm{ARCH}$ & $\begin{array}{c}0.050^{* * * *} \\
(0.012)\end{array}$ & $\begin{array}{c}0.049^{* * * *} \\
(0.011)\end{array}$ & 0.06 & $\begin{array}{c}0.094^{* * * *} \\
(0.013)\end{array}$ & $\begin{array}{c}0.077 \\
(0.081)\end{array}$ & $\begin{array}{c}0.036 \\
(0.059)\end{array}$ & $\begin{array}{c}0.079 \\
(0.083)\end{array}$ & $\begin{array}{c}0.036^{* * * *} \\
(0.007)\end{array}$ & $\begin{array}{c}0.037^{* * * *} \\
(0.006)\end{array}$ & 0.06 & $\begin{array}{c}0.093^{* * * *} \\
(0.013)\end{array}$ & $\begin{array}{c}0.072 \\
(0.053)\end{array}$ & $\begin{array}{c}0.074 \\
(0.062)\end{array}$ & $\begin{array}{c}0.069 \\
(0.052)\end{array}$ \\
\hline GARCH & $\begin{array}{c}0.950^{* * * *} \\
(0.011)\end{array}$ & $\begin{array}{c}0.950^{* * * *} \\
(0.012)\end{array}$ & 0.94 & $\begin{array}{c}0.974^{* * * *} \\
(0.002)\end{array}$ & $\begin{array}{c}0.961^{\text {***** }} \\
(0.022)\end{array}$ & $\begin{array}{c}0.957^{\text {****** }} \\
(0.016)\end{array}$ & $\begin{array}{c}0.961^{* * * *} \\
(0.023)\end{array}$ & $\begin{array}{c}0.963^{* * * *} \\
(0.006)\end{array}$ & $\begin{array}{c}0.963^{* * * *} \\
(0.08)\end{array}$ & 0.94 & $\begin{array}{l}0.970^{* * * *} \\
(0.004)\end{array}$ & $\begin{array}{c}0.964^{* * * *} \\
(0.011)\end{array}$ & $\begin{array}{c}0.949^{* * * *} \\
(0.021)\end{array}$ & $\begin{array}{c}0.964^{* * * *} \\
(0.010)\end{array}$ \\
\hline $\operatorname{EGARCH}(\delta)$ & & & & $\begin{array}{l}0.050^{* * * *} \\
(0.009)\end{array}$ & & & & & & & $\begin{array}{l}0.038^{* * * *} \\
(0.009)\end{array}$ & & & \\
\hline$d$ & & & & & $\begin{array}{c}0.502^{* * *} \\
(0.047)\end{array}$ & $\begin{array}{c}0.496^{* * *} \\
(0.028)\end{array}$ & $\begin{array}{c}0.454^{* * *} \\
(0.097)\end{array}$ & & & & & $\begin{array}{c}0.490^{* * *} \\
(0.028)\end{array}$ & $\begin{array}{c}0.470^{* * *} \\
(0.038)\end{array}$ & $\begin{array}{c}0.490^{* * *} \\
(0.026)\end{array}$ \\
\hline $\operatorname{APARCH}(\gamma)$ & & & & & & $\begin{array}{c}-0.413^{* * * *} \\
(0.194)\end{array}$ & & & & & & & $\begin{array}{c}-0.291^{* * *} \\
(0.112)\end{array}$ & \\
\hline $\operatorname{APARCH}(\delta)$ & & & & & & $\begin{array}{c}1.702^{* * * *} \\
(0.224)\end{array}$ & & & & & & & $\begin{array}{l}1.866^{* * * *} \\
(0.169)\end{array}$ & \\
\hline Student- $d f$ & $\begin{array}{c}4.498^{* * * *} \\
(0.389)\end{array}$ & $\begin{array}{c}4.540^{* * * *} \\
(0.325)\end{array}$ & $\begin{array}{c}5.252^{* * * *} \\
(0.352)\end{array}$ & $\begin{array}{c}4.497^{* * * *} \\
(0.383)\end{array}$ & $\begin{array}{c}4.597^{* * * *} \\
(0.340)\end{array}$ & $\begin{array}{c}4.654^{* * * *} \\
(0.385)\end{array}$ & $\begin{array}{c}4.563^{* * *} \\
(0.404)\end{array}$ & $\begin{array}{c}4.142^{* * * *} \\
(0.341)\end{array}$ & $\begin{array}{c}4.102^{* * * *} \\
(0.274)\end{array}$ & $\begin{array}{c}4.875^{* * *} \\
(0.307)\end{array}$ & $\begin{array}{c}4.279^{* * * *} \\
(0.359)\end{array}$ & $\begin{array}{c}4.146^{* * * *} \\
(0.283)\end{array}$ & $\begin{array}{c}4.365^{* * * *} \\
(0.348)\end{array}$ & $\begin{array}{c}4.202^{* * * *} \\
(0.348)\end{array}$ \\
\hline$\underline{\log (L)}$ & 7892.35 & 7892.33 & 7881.49 & 7843.66 & 7897.08 & 7910.23 & 7879.1 & 7983.44 & 7983.42 & 7.965 .21 & 7919.98 & 7986.37 & 7993.38 & 7986.41 \\
\hline \multicolumn{15}{|c|}{ Diagnostic tests } \\
\hline AIC & -5.473 & -5.473 & -5.467 & -5.438 & -5.475 & -5.483 & -5.475 & -5.536 & -5.537 & -5.525 & -5.491 & -5.537 & -5.541 & -5.536 \\
\hline SIC & -5.460 & -5.463 & -5.461 & -5.421 & -5.461 & -5.464 & -5.458 & -5.523 & -5.526 & -5.519 & -5.474 & -5.523 & -5.527 & -5.520 \\
\hline $\mathrm{ARCH}(5)$ & $\begin{array}{l}1.196 \\
{[0.09]}\end{array}$ & $\begin{array}{c}1.197 \\
{[0.09]} \\
\end{array}$ & $\begin{array}{l}3.657 \\
0.02]\end{array}$ & $\begin{array}{c}1.807 \\
{[0.108]}\end{array}$ & $\begin{array}{l}1.166 \\
{[0.20]} \\
\end{array}$ & $\begin{array}{c}1.191 \\
{[0.10]}\end{array}$ & $\begin{array}{c}1.165 \\
{[0.20]} \\
\end{array}$ & $\begin{array}{l}1.041 \\
{[0.37]} \\
\end{array}$ & $\begin{array}{c}1.042 \\
{[0.37]} \\
\end{array}$ & $\begin{array}{c}1.044 \\
{[0.36]} \\
\end{array}$ & $\begin{array}{c}1.046 \\
{[0.35]} \\
\end{array}$ & $\begin{array}{c}1.088 \\
{[0.31]} \\
\end{array}$ & $\begin{array}{c}1.047 \\
{[0.35]}\end{array}$ & $\begin{array}{c}1.047 \\
{[0.35]} \\
\end{array}$ \\
\hline$\overline{Q^{2}(10)}$ & $\begin{array}{c}6.15 \\
{[0.72]}\end{array}$ & $\begin{array}{c}6.14 \\
{[0.72]}\end{array}$ & $\begin{array}{l}23.48 \\
{[0.00]} \\
\end{array}$ & $\begin{array}{c}13.99 \\
{[0.081]}\end{array}$ & $\begin{array}{c}14.5 \\
{[0.07]} \\
\end{array}$ & $\begin{array}{c}7.63 \\
{[0.57]} \\
\end{array}$ & $\begin{array}{c}6.27 \\
{[0.71]} \\
\end{array}$ & $\begin{array}{c}9.05 \\
{[0.43]} \\
\end{array}$ & $\begin{array}{c}9.03 \\
{[0.43]} \\
\end{array}$ & $\begin{array}{c}9.16 \\
{[0.42]} \\
\end{array}$ & $\begin{array}{c}9.21 \\
{[0.41]} \\
\end{array}$ & $\begin{array}{c}9.15 \\
{[0.42]} \\
\end{array}$ & $\begin{array}{c}10.7 \\
{[0.29]} \\
\end{array}$ & $\begin{array}{c}9.17 \\
{[0.42]} \\
\end{array}$ \\
\hline $\mathrm{Q}(10)$ & $\begin{array}{l}6.458 \\
{[0.69]}\end{array}$ & $\begin{array}{l}6.215 \\
{[0.72]}\end{array}$ & $\begin{array}{l}7.296 \\
{[0.61]}\end{array}$ & $\begin{array}{l}10.528 \\
{[0.31]}\end{array}$ & $\begin{array}{l}7.360 \\
{[0.60]}\end{array}$ & $\begin{array}{l}9.114 \\
{[0.43]}\end{array}$ & $\begin{array}{l}7.316 \\
{[0.60]}\end{array}$ & $\begin{array}{l}7.141 \\
{[0.62]}\end{array}$ & $\begin{array}{l}7.054 \\
{[0.63]}\end{array}$ & $\begin{array}{c}7.611 \\
{[0.57]}\end{array}$ & $\begin{array}{c}11.165 \\
{[0.264]}\end{array}$ & $\begin{array}{c}7.971 \\
{[0.537]}\end{array}$ & $\begin{array}{c}8.523 \\
{[0.482]}\end{array}$ & $\begin{array}{c}7.712 \\
{[0.563]}\end{array}$ \\
\hline$\overline{\mathrm{JB}}$ & $\begin{array}{c}1196 \\
{[0.00]}\end{array}$ & $\begin{array}{c}1239 \\
{[0.00]}\end{array}$ & $\begin{array}{c}1137 \\
{[0.00]}\end{array}$ & $\begin{array}{c}2843 \\
{[0.00]}\end{array}$ & $\begin{array}{c}1508 \\
{[0.00]}\end{array}$ & $\begin{array}{c}1530 \\
{[0.00]}\end{array}$ & $\begin{array}{c}1425 \\
{[0.00]}\end{array}$ & $\begin{array}{c}2063 \\
{[0.00]}\end{array}$ & $\begin{array}{c}2123 \\
{[0.00]}\end{array}$ & $\begin{array}{c}1712 \\
{[0.00]}\end{array}$ & $\begin{array}{c}1804 \\
{[0.00]}\end{array}$ & $\begin{array}{c}1725 \\
{[0.00]}\end{array}$ & $\begin{array}{c}1479 \\
{[0.00]}\end{array}$ & $\begin{array}{c}1692 \\
{[0.00]}\end{array}$ \\
\hline
\end{tabular}

Notes: The table reports the estimation results of GARCH-class models for natural gas spot and futures returns. We consider seven competing models: standard GARCH, IGARCH, RiskMetrics (RM), EGARCH, FIGARCH, FIAPARCH, and HYGARCH. Const (m) and Const (v) refer to the constant terms in mean and variance equations. Standard errors of estimates are reported in parentheses. $\mathrm{Q}^{2}(10)$ and $\mathrm{ARCH}(5)$ are the empirical statistics of the Ljung-Box test for autocorrelation with 10 lags applied to squared standardized residuals and the Engle (1982) test for conditional heteroscedasticity applied to standardized residuals, respectively. The $p$-values associated with the statistical tests are presented in brackets. ${ }^{*}{ }^{* * *}$ and ${ }^{* * *}$ denote the significance at $10 \%, 5 \%$ and $1 \%$ levels, respectively. 
The results for silver are similar to those of gold in almost all aspects (Table 7), except for the fact that we find stronger and more abundant evidence of return predictability for silver. This is not surprising because gold is much less volatile than silver. Indeed, the current spot and futures returns are significantly and negatively associated with one-period lagged returns in 13 out of 14 cases. This finding may reflect the continual mean-reverting corrections of silver prices over the estimation period. As for gold, the FIAPARCH model is also identified as the most suitable for modeling the volatility of silver spot and futures returns.

Summarizing all, our estimation results show that the FIAPARCH model is preferred to the other six competing models in terms of volatility estimates for all spot return series, but only in three out of four cases for the futures return series. The standard GARCH model is selected for the natural gas futures returns only. With the parameters of its volatility process already fixed in advance, the RiskMetrics model seems to be the least meaningful risk management tool economically as is the case in stock markets. We think that the superiority of the FIAPARCH model stems from its ability to satisfactorily capture both asymmetric effects and LM patterns in the dynamics of commodity volatility processes. The estimated tail parameters (Student- $d f$ ) as well as the results of diagnostic tests applied to standardized residuals and standardized squared residuals indicate that our selected GARCH-type models with Student- $t$ distributions are correctly specified because the hypotheses of no autocorrelation and no remaining ARCH effects cannot be rejected in almost all cases. In addition, even though residual series still depart from normality, the values of Jarque-Bera statistics are generally much lower than those of the raw returns.

\subsection{Forecasting performance}

We use the rolling forecasting methodology to generate the one- and twenty-day-ahead volatility forecasts of the seven competing GARCH-type models with Student- $t$ distributions over the out-of-sample period from January 1, 2010 to March 31, 2011. We then compare their forecasting performance based on two mean loss functions (MSE and MAPE). Table 8 reports the obtained results, while the bold face numbers indicate the best model in terms of volatility forecast accuracy.

Regarding the one-day forecasting horizon, we can see that no single model is found to absolutely outperform the other models. The EGARCH, FIAPARCH, HYGARCH, and FIGARCH models are selected for the spot returns of crude oil, natural gas, gold, and silver, respectively. For the futures returns, the evaluation criteria select the FIAPARCH for crude 
oil and silver, but EGARCH for natural gas and FIGARCH for gold. Altogether, the nonlinear GARCH-type models which are able to capture the two important empirical features of commodity returns (asymmetry and/or long memory in volatility) display, however, greater forecasting accuracy than the linear ones. Indeed, the MAE and MAPE never select the standard GARCH, IGARCH and RiskMetrics for the eight returns series we consider over the out-ofsample period. Our findings for crude oil are thus not in line with those of Wei et al. (2010) who show that the linear GARCH-type models are more useful than the nonlinear ones for the short-run volatility forecasting.

Table 8

Comparison of volatility forecasts across competing models

\begin{tabular}{|c|c|c|c|c|c|c|c|c|c|}
\hline \multirow{2}{*}{ Model } & \multirow{2}{*}{ Criteria } & \multicolumn{2}{|c|}{ Crude oil } & \multicolumn{2}{|c|}{ Natural gas } & \multicolumn{2}{|c|}{ Gold } & \multicolumn{2}{|c|}{ Silver } \\
\hline & & Spot & Futures & Spot & Futures & Spot & Futures & Spot & Futures \\
\hline \multicolumn{10}{|c|}{ One-day horizon } \\
\hline \multirow[t]{2}{*}{ GARCH } & MAE & 0.113 & 0.057 & 0.064 & 0.159 & 0.351 & 0.484 & 0.319 & 2.230 \\
\hline & MAPE & 0.419 & 0.240 & 0.331 & 0.582 & 0.698 & 0.786 & 135.5 & 0.871 \\
\hline \multirow[t]{2}{*}{ IGARCH } & MAE & 0.102 & 0.064 & 0.051 & 0.136 & 0.354 & 0.482 & 0.317 & 2.227 \\
\hline & MAPE & 0.380 & 0.270 & 0.264 & 0.496 & 0.703 & 0.784 & 134.4 & 0.869 \\
\hline \multirow[t]{2}{*}{ RM } & MAE & 0.158 & 0.061 & 0.065 & 0.149 & 0.367 & 0.501 & 0.377 & 2.279 \\
\hline & MAPE & 0.680 & 0.294 & 0.355 & 0.545 & 0.759 & 0.814 & 137.8 & 0.889 \\
\hline \multirow[t]{2}{*}{ EGARCH } & MAE & 0.093 & 0.147 & 0.059 & 0.141 & 0.389 & 0.488 & 0.326 & 2.238 \\
\hline & MAPE & 0.227 & 0.301 & 0.281 & 0.452 & 0.775 & 0.794 & 138.1 & 0.866 \\
\hline \multirow[t]{2}{*}{ FIGARCH } & MAE & 0.201 & 0.117 & 0.052 & 0.158 & 0.353 & 0.481 & $\mathbf{0 . 3 1 7}$ & 2.214 \\
\hline & MAPE & 0.746 & 0.495 & 0.270 & 0.576 & 0.702 & 0.783 & 134.2 & 0.864 \\
\hline \multirow[t]{2}{*}{ FIAPARCH } & MAE & 0.112 & 0.051 & 0.051 & 0.161 & 0.372 & 0.492 & 0.367 & 2.190 \\
\hline & MAPE & 0.418 & 0.217 & 0.263 & 0.588 & 0.742 & 0.799 & 155.6 & 0.855 \\
\hline \multirow[t]{2}{*}{ HYGARCH } & MAE & 0.180 & 0.087 & 0.067 & 0.160 & 0.350 & 0.484 & 0.319 & 2.219 \\
\hline & MAPE & 0.671 & 0.365 & 0.348 & 0.585 & 0.696 & 0.787 & 135.7 & 0.866 \\
\hline \multicolumn{10}{|c|}{ 20-day horizon } \\
\hline \multirow[t]{2}{*}{ GARCH } & MAE & 0.270 & 0.236 & 0.355 & 0.083 & 0.186 & 0.229 & 0.557 & 0.424 \\
\hline & MAPE & 75.8 & 24.38 & 14.17 & 18.12 & 31.13 & 49.40 & 841.2 & 88.77 \\
\hline \multirow[t]{2}{*}{ IGARCH } & MAE & 0.265 & 0.238 & 0.385 & 0.101 & 0.186 & 0.229 & 0.556 & 0.617 \\
\hline & MAPE & 74.28 & 24.86 & 18.05 & 24.79 & 30.47 & 50.31 & 830.0 & 90.36 \\
\hline \multirow[t]{2}{*}{ RM } & MAE & 0.283 & 0.299 & 0.414 & 0.097 & 0.184 & 0.301 & 0.572 & 0.623 \\
\hline & MAPE & 78.88 & 28.57 & 18.84 & 20.72 & 26.96 & 49.78 & 906.4 & 93.17 \\
\hline \multirow[t]{2}{*}{ EGARCH } & MAE & 0.248 & 0.245 & 0.363 & 0.093 & 0.187 & 0.377 & 0.463 & 0.496 \\
\hline & MAPE & 44.43 & 29.14 & 15.95 & 22.57 & 59.31 & 56.04 & 790.1 & 93.77 \\
\hline \multirow[t]{2}{*}{ FIGARCH } & MAE & 0.398 & 0.284 & 0.379 & 0.088 & 0.186 & 0.229 & 0.559 & 0.413 \\
\hline & MAPE & 106.5 & 31.94 & 17.34 & 19.75 & 30.59 & 50.32 & 885.0 & 91.89 \\
\hline \multirow[t]{2}{*}{ FIAPARCH } & MAE & 0.325 & 0.247 & 0.348 & 0.084 & 0.183 & 0.227 & 0.565 & 0.398 \\
\hline & MAPE & 91.72 & 26.16 & 13.65 & 18.35 & 25.42 & 44.49 & 964.5 & 86.22 \\
\hline \multirow[t]{2}{*}{ HYGARCH } & MAE & 0.374 & 0.261 & 0.341 & 0.087 & 0.186 & 0.229 & 0.560 & 0.616 \\
\hline & MAPE & 101.6 & 29.04 & 12.35 & 19.37 & 31.28 & 49.41 & 894.2 & 89.67 \\
\hline
\end{tabular}

Notes: This table reports the mean losses of the different volatility models over the out-of-sample period with respect to two evaluation criteria (MAE and MAPE). The values in bold face indicate the best-performing models (i.e., models with the lowest mean losses).

The results for the twenty-day forecasting horizon also reject the hypothesis that a single model is absolutely better than the remaining models in terms of lowest mean losses. The forecasting evaluation criteria select the FIAPARCH for three return series (spot gold, and gold and silver futures), followed by the EGARCH and GARCH models which provide the best volatility forecasts for two return series each. While the short memory GARCH model has the lowest mean losses for crude oil and natural gas futures returns, the EGARCH model 
is relevant for crude oil and silver spot returns. The HYGARCH model generates more accurate forecasts than the other models for only one series (natural gas spot returns). Even though our findings point to the superiority of the nonlinear GARCH models over the longer horizon (twenty-day forecasting) relative to the linear models, the correct choice of a GARCH-type specification appears to be a challenging task since none of the nonlinear models considered absolutely outperforms the others. Moreover, the best volatility model often differs even for the same commodity. Such differences give better opportunities for arbitrage on the commodities markets and require market participants to carefully check the relevance of a particular GARCH model before making use of it.

\subsection{Role of long memory and asymmetry in VaR estimations}

As far as the market risk matters, investors may wish to know the best suitable model that they can use to forecast the $V a R$ of their asset portfolios. Given that our previous forecasting exercise gives rise to the suitability of the nonlinear GARCH-type models which can capture the asymmetric volatility effects and/or LM property, we now produce the $V a R$ estimates and forecasts from two GARCH models with Student- $t$ distributions: EGARCH and FIAPARCH. The standard GARCH model is also considered for comparison purposes. By doing so, we are able to check the accuracy of the models that take into account the long memory and asymmetry characteristics in computing the $\operatorname{VaR}$.

The in-sample VaR estimates and the out-of-sample VaR forecasts for both short and long trading horizons are generated for different $\alpha$ levels ranging from $5 \%$ to $0.25 \%$. The accuracy of different GARCH-VaR models is then investigated by using the Kupiec likelihood ratio (LR) test that compares the failure rate for both the left and right tails to the pre-specified $V a R$ level. The best model refers to the one for which the empirical failure rate is equal to the pre-specified level. The use of a correctly specified model will permit the investors to accurately forecast their possible trading losses.

\subsubsection{In-sample VaR estimations}

Table 9 presents the in-sample $\operatorname{VaR}$ estimations for the four commodities using the standard GARCH, EGARCH and FIAPARCH models where the standard GARCH is used as the baseline model. Each of these models provides the empirical failure rates and the Kupiec LR statistics together with their associated $p$-values.

The results show that the standard GARCH model performs poorly for both long and short trading positions, regardless of the commodity asset considered because the Kupiec test 
statistics reject the null hypothesis at the three conventional levels $(1 \%, 5 \%$ and $10 \%)$ in most cases. The GARCH model only seems to be appropriate for spot gold. From Table 10, we see that the use of EGARCH model leads to a clear improvement of the in-sample VaR estimations relative to the GARCH model for two commodity return series (natural gas futures and spot silver), whatever the undertaken trading action is (buy or sell). For the other return series, the EGARCH model is not better than the standard GARCH model. When the long memory and asymmetric effects are accounted for in the FIGARCH model, the Kupiec LR test fails to reject the null hypothesis for all $\alpha$ significance levels and for all commodity return series, except the $99 \% \mathrm{VaR}$ for the short trading positions in crude oil futures returns. However, the rejection of the null hypothesis is only statistically significant at the $10 \%$ level. These findings lead us to conclude that the $\operatorname{VaR}$ estimates provided by the FIAPARCH are more accurate than those of the GARCH and EGARCH models over the in-sample period. Our results are thus consistent with those of Aloui and Mabrouk (2010), suggesting that volatility models with long memory and asymmetry improve the quality of $V a R$ estimations. Indeed, Aloui and Mabrouk (2010) consider four petroleum commodity markets (Brent crude oil, WTI crude oil, New York regular gasoline, and Rotterdam regular gasoline) over the period May 1987 - July 2007. They find that the FIAPARCH model performs well for the in-sample VaR estimations for both long and short positions.

\subsubsection{Out-of-sample $V a R$ estimations}

Table 10 reports the out-of-sample $V a R$ evaluations for the standard GARCH, EGARCH and FIAPARCH models. The obtained results are almost similar to the in-sample VaR computations. The quality of the $\operatorname{VaR}$ forecasts by the GARCH model is not better than that of the insample period. The EGARCH model performs slightly better out-of-sample than it does insample, in particular for the following series: spot silver, silver futures, spot gold, gold futures, and spot natural gas.

As to the FIAPARCH model, it outperforms the other models in terms of the accuracy of $\mathrm{VaR}$ forecasts for the short trading position as the null hypothesis is not rejected in all cases according to the Kupiec test. Its forecasting accuracy for the long trading positions is only rejected in several cases: silver futures (at the $99.5 \%$ and $99.75 \%$ confidence levels), natural gas futures (at the $99.5 \%$ and $99.75 \%$ confidence levels), and spot natural gas (at the $99 \%$ confidence level). Overall, these findings show the superior performance of the FIAPARCH over the standard GARCH and EGARCH models in forecasting the VaR for spot and futures returns of the major commodities we consider. They thus suggest that accommodating long 
memory and asymmetry properties in the model lead to an increase in the accuracy of $V a R$ forecasts.

Table 9

Accuracy of in-sample VaR estimations

\begin{tabular}{|c|c|c|c|c|c|c|c|}
\hline \multirow{2}{*}{$\alpha$ quantile } & \multicolumn{3}{|c|}{ Short trading position } & \multirow[b]{2}{*}{$\alpha$ quantile } & \multicolumn{3}{|c|}{ Long trading position } \\
\hline & GARCH & EGARCH & FIAPARCH & & GARCH & EGARCH & FIAPARCH \\
\hline \multicolumn{4}{|c|}{ Spot crude oil } & \multicolumn{4}{|c|}{ Spot crude oil } \\
\hline 0.95 & $4.2583^{++}$ & $3.9317^{++}$ & 0.6260 & 0.05 & 1.6198 & 1.2613 & 0.3102 \\
\hline 0.975 & 1.7652 & $3.5986^{+}$ & 0.4382 & 0.025 & 1.2201 & $0.11 \mathrm{e}-3$ & 0.1118 \\
\hline 0.99 & $3.5824^{+}$ & $4.3384^{++}$ & 2.3090 & 0.01 & 0.3105 & 1.8433 & 0.0774 \\
\hline 0.995 & 0.8887 & 1.4469 & 0.0385 & 0.005 & 0.9166 & $3.3032^{+}$ & 1.3855 \\
\hline 0.9975 & 0.1285 & 1.0774 & $9.08 \mathrm{e}-04$ & 0.0025 & $4.5674^{++}$ & $4.5674^{++}$ & 2.4800 \\
\hline \multicolumn{4}{|c|}{ Crude oil futures } & \multicolumn{4}{|c|}{ Crude oil futures } \\
\hline 0.95 & 1.4032 & 0.2296 & 0.3545 & 0.05 & 1.2613 & 0.6762 & 0.0608 \\
\hline 0.975 & $3.5986^{+}$ & $6.7394^{+++}$ & 0.7786 & 0.025 & $3.1024^{+}$ & 0.3924 & $1.15 \mathrm{e}-04$ \\
\hline 0.99 & $7.1249^{+++}$ & $2.9070^{+}$ & $2.9070^{+}$ & 0.01 & 0.7766 & $3.9057^{++}$ & 0.0036 \\
\hline 0.995 & 1.4469 & 1.4469 & 0.0385 & 0.005 & 0.2578 & 0.2578 & 0.4741 \\
\hline 0.9975 & 1.0774 & $3.4197^{+}$ & 0.1285 & 0.0025 & 0.9683 & 0.9683 & 0.1285 \\
\hline \multicolumn{4}{|c|}{ Spot natural gas } & \multicolumn{4}{|c|}{ Spot natural gas } \\
\hline 0.95 & 1.1158 & $3.6777^{+}$ & 0.1165 & $\overline{0.05}$ & $4.3927^{++}$ & 1.8860 & 0.1237 \\
\hline 0.975 & 0.3095 & 0.2031 & 0.3937 & 0.025 & 0.0366 & $3.4719^{+}$ & 0.5440 \\
\hline 0.99 & 2.3620 & 0.5509 & 0.0074 & 0.01 & 1.9055 & 7.0175 & 1.7299 \\
\hline 0.995 & $9.2679^{+++}$ & 1.9876 & 0.2740 & 0.005 & $4.1694^{++}$ & $2.9899^{+}$ & 2.1171 \\
\hline 0.9975 & $13.735^{+++}$ & 1.6770 & 0.0017 & 0.0025 & 2.5175 & $3^{3839}{ }^{+}$ & 1.0562 \\
\hline \multicolumn{4}{|c|}{ Natural gas futures } & \multicolumn{4}{|c|}{ Natural gas futures } \\
\hline 0.95 & 3.1326 $^{+}$ & 0.0124 & 0.5208 & $\overline{0.05}$ & $2.8657^{+}$ & 0.1844 & 0.0652 \\
\hline 0.975 & 1.1652 & 0.1669 & 0.5439 & 0.025 & 1.9806 & 0.9197 & 0.9197 \\
\hline 0.99 & 0.5509 & 0.0074 & 0.0658 & 0.01 & $3.5045^{+}$ & 0.6045 & 0.1835 \\
\hline 0.995 & 2.6353 & 0.5629 & 0.5629 & 0.005 & $2.9899^{+}$ & 0.9609 & 0.0 .27 \\
\hline 0.9975 & 1.6770 & 0.0899 & 0.9910 & 0.0025 & 3.3839 $^{+}$ & 0.4295 & 0.0899 \\
\hline \multicolumn{4}{|l|}{ Spot gold } & \multicolumn{4}{|l|}{ Spot gold } \\
\hline 0.95 & 0.3463 & 0.0909 & 0.1832 & 0.05 & 0.3463 & 1.1365 & 2.3668 \\
\hline 0.975 & 0.1258 & 0.1056 & 0.1055 & 0.025 & 0.2178 & 0.4741 & 0.1258 \\
\hline 0.99 & 1.6461 & $5.2000^{++}$ & 0.2821 & 0.01 & $1.13 \mathrm{e}-04$ & 0.2821 & 0.1314 \\
\hline 0.995 & 0.5929 & 1.7458 & 1.7458 & 0.005 & 0.0604 & 1.7458 & 0.5445 \\
\hline 0.9975 & 0.5416 & 1.2915 & $2.82 \mathrm{e}-05$ & 0.0025 & $4.1041^{++}$ & $4.1041^{++}$ & 0.1242 \\
\hline \multicolumn{4}{|c|}{ Gold futures } & \multicolumn{4}{|c|}{ Gold futures } \\
\hline 0.95 & 4.9701 & 1.0909 & 0.3463 & 0.05 & 1.6975 & 2.6136 & 1.9087 \\
\hline 0.975 & 0.4504 & 2.2417 & 0.1258 & 0.025 & 0.1258 & 1.5281 & 2.4356 \\
\hline 0.99 & 1.4726 & $6.1949^{++}$ & 0.8145 & 0.01 & 0.0351 & 0.5122 & 0.7704 \\
\hline 0.995 & 2.7355 & 1.7458 & 0.5929 & 0.005 & $5.66 \mathrm{e}-05$ & 0.2548 & 0.5445 \\
\hline 0.9975 & 6.2309 & $2.82 \mathrm{e}-05$ & 0.4717 & 0.0025 & 1.2915 & $4.1041^{++}$ & 0.1242 \\
\hline \multicolumn{4}{|l|}{ Spot silver } & \multicolumn{4}{|l|}{ Spot silver } \\
\hline 0.95 & 0.8235 & 0.0909 & $\overline{0.0111}$ & 0.05 & 0.2998 & 0.4468 & 0.0713 \\
\hline 0.975 & 1.8090 & 1.2995 & 0.0169 & 0.025 & 0.3083 & $2.88 \mathrm{e}-04$ & 1.2719 \\
\hline 0.99 & 0.5007 & 1.6461 & 0.2872 & 0.01 & 0.8145 & 0.1314 & 0.2872 \\
\hline 0.995 & 23.750 & 1.7458 & $5.66 \mathrm{e}-05$ & 0.005 & 0.0604 & 0.5929 & 0.2490 \\
\hline 0.9975 & 27.870 & 0.4452 & 0.5416 & 0.0025 & 0.1271 & 0.1271 & $2.82 \mathrm{e}-05$ \\
\hline \multicolumn{4}{|c|}{ Silver futures } & \multicolumn{4}{|c|}{ Silver futures } \\
\hline 0.95 & 3.2469 & $4.5945^{++}$ & 0.9239 & $\overline{0.05}$ & $7.2789^{+++}$ & $8.5636^{+++}$ & 0.3463 \\
\hline 0.975 & 5.5296 & $4.4282^{++}$ & 2.2417 & 0.025 & $4.3821^{++}$ & $5.3080^{++}$ & 0.0443 \\
\hline 0.99 & 5.2000 & $6.1949^{++}$ & 0.8145 & 0.01 & $3.4901^{+}$ & 0.0351 & 0.2872 \\
\hline 0.995 & 2.5887 & $3.6325^{+}$ & 1.0856 & 0.005 & 2.0460 & 0.2490 & 0.9459 \\
\hline 0.9975 & 1.2915 & $4.1041^{++}$ & 0.5416 & 0.0025 & $2.82 \mathrm{e}-05$ & 0.1242 & 1.7513 \\
\hline
\end{tabular}

Notes: The table reports the empirical statistics of the Kupiec test that examines whether the empirical failure rate is equal to the pre-specified VaR level. The bold face numbers indicate the rejection of the null hypothesis at the $1 \%\left({ }^{++}\right), 5 \%\left({ }^{++}\right)$and $10 \%\left({ }^{+}\right)$. The best model is the one with the least rejections. 
Table 10

Accuracy of out-of-sample VaR estimations

\begin{tabular}{|c|c|c|c|c|c|c|c|}
\hline \multicolumn{4}{|c|}{ Short trading position } & \multicolumn{4}{|c|}{ Long trading position } \\
\hline$\alpha$ quantile & GARCH & EGARCH & FIAPARCH & $\alpha$ quantile & GARCH & EGARCH & FIAPARCH \\
\hline \multicolumn{4}{|c|}{ Spot crude oil } & \multicolumn{4}{|c|}{ Spot crude oil } \\
\hline 0.95 & $\mathbf{3 . 1 5 6 3}^{+}$ & 2.0778 & 0.2053 & 0.05 & 1.4915 & 1.6884 & 0.6081 \\
\hline 0.975 & 1.1341 & $2.7416^{+}$ & 0.0214 & 0.025 & 0.8995 & 0.0362 & 0.3621 \\
\hline 0.99 & $4.7132^{++}$ & $3.8786^{++}$ & 2.4801 & 0.01 & 0.8848 & 2.5563 & 0.0670 \\
\hline 0.995 & 1.2344 & 1.9307 & 0.3314 & 0.005 & 1.8329 & $4.0520^{++}$ & 1.8329 \\
\hline 0.9975 & 0.0021 & 1.4018 & 0.0021 & 0.0025 & $4.6492^{++}$ & $3.4885^{+}$ & 3.4885 \\
\hline \multicolumn{4}{|c|}{ Crude oil futures } & \multicolumn{4}{|c|}{ Crude oil futures } \\
\hline 0.95 & 1.2304 & 0.7428 & 0.6865 & 0.05 & 0.0439 & 0.0371 & 0.0439 \\
\hline 0.975 & 0.3621 & 2.0102 & 0.0011 & 0.025 & 2.5791 & 0.9233 & 0.0011 \\
\hline 0.99 & 0.2025 & 0.2025 & 2.1843 & 0.01 & $9.0433^{+++}$ & $10.945^{+++}$ & 0.0084 \\
\hline 0.995 & 0.1808 & 2.4862 & 0.0042 & 0.005 & $10.595^{+++}$ & $14.778^{+++}$ & 0.3314 \\
\hline 0.9975 & $4.6492^{++}$ & 2.4714 & 0.6157 & 0.0025 & $10.554^{+++}$ & $14.168^{+++}$ & 0.4016 \\
\hline \multicolumn{4}{|c|}{ Spot natural gas } & \multicolumn{4}{|c|}{ Spot natural gas } \\
\hline 0.95 & 1.1187 & $\mathbf{3 . 5 9 5 2}^{+}$ & 0.4147 & 0.05 & $4.2597^{++}$ & 4.2597 & 0.0568 \\
\hline 0.975 & 1.2247 & 0.0132 & 0.0498 & 0.025 & 0.1135 & 1.3141 & 0.8327 \\
\hline 0.99 & 1.6805 & 1.2792 & 0.0611 & 0.01 & 1.6805 & 2.6337 & $3.0591^{+}$ \\
\hline 0.995 & $7.0934^{+++}$ & 0.4624 & 0.0395 & 0.005 & 2.5408 & 2.5408 & 1.2004 \\
\hline 0.9975 & $14.271^{+++}$ & 0.9371 & 0.0012 & 0.0025 & $3.5358^{+}$ & 1.6401 & 0.5988 \\
\hline \multicolumn{4}{|c|}{ Natural gas futures } & \multicolumn{4}{|c|}{ Natural gas futures } \\
\hline 0.95 & $4.2032^{++}$ & 0.2351 & 0.9224 & 0.05 & 1.7077 & 1.3008 & 0.0071 \\
\hline 0.975 & 0.2020 & 0.2034 & 0.0498 & 0.025 & 1.0592 & 1.5978 & 0.2034 \\
\hline 0.99 & 1.2792 & 0.0048 & 0.0047 & 0.01 & 2.4117 & $5.5431^{++}$ & 1.6805 \\
\hline 0.995 & 2.5408 & 0.0396 & 0.4624 & 0.005 & $2.7596^{+}$ & $\mathbf{3 . 8 3 1 4}^{+}$ & $4.1227^{++}$ \\
\hline 0.9975 & 1.6401 & 0.5988 & 0.9371 & 0.0025 & $4.2454^{++}$ & 2.5581 & $7.4359^{+++}$ \\
\hline \multicolumn{4}{|l|}{ Spot gold } & \multicolumn{4}{|l|}{ Spot gold } \\
\hline 0.95 & 1.9643 & 0.0707 & 0.2511 & 0.05 & 2.7845 & 0.1735 & 1.1827 \\
\hline 0.975 & 1.6285 & $3.55 e-5$ & 0.0537 & 0.025 & 1.6285 & 0.2182 & 0.2182 \\
\hline 0.99 & $6.1218^{++}$ & 3.0537 & 0.1186 & 0.01 & $9.7294^{+++}$ & 0.5354 & 0.5850 \\
\hline 0.995 & $8.7827^{+++}$ & 0.4296 & 1.5200 & 0.005 & $30.726^{+++}$ & 2.3576 & 0.4422 \\
\hline 0.9975 & $7.9670^{+++}$ & $3.1592^{+}$ & 0.0848 & 0.0025 & $31.884^{+++}$ & 0.2143 & 0.2143 \\
\hline \multicolumn{4}{|c|}{ Gold futures } & \multicolumn{4}{|c|}{ Gold futures } \\
\hline 0.95 & 0.1922 & 0.3327 & 0.1922 & 0.05 & 0.4482 & 0.0544 & 1.5714 \\
\hline 0.975 & 0.9579 & 0.0047 & 0.1343 & 0.025 & 0.0158 & 1.7602 & 2.2592 \\
\hline 0.99 & $3.0537^{+}$ & 0.5014 & 3.0537 & 0.01 & 0.1186 & $3.3965^{+}$ & 0.0481 \\
\hline 0.995 & 0.8835 & 0.8399 & 0.4296 & 0.005 & 0.4296 & $9.23 e-04$ & 0.1702 \\
\hline 0.9975 & 0.0059 & 2.6489 & 0.4152 & 0.0025 & 0.7583 & 0.4186 & 1.7057 \\
\hline \multicolumn{4}{|l|}{ Spot silver } & \multicolumn{4}{|l|}{ Spot silver } \\
\hline 0.95 & 0.0610 & 0.6174 & 0.1102 & 0.05 & $7.31 \mathrm{e}-05$ & 0.4482 & 0.1735 \\
\hline 0.975 & 0.2378 & 2.1897 & 0.2378 & 0.025 & 0.3413 & $3.55 \mathrm{e}-05$ & 0.8691 \\
\hline 0.99 & 8.7603 & 1.2754 & 0.8892 & 0.01 & 0.0238 & 0.0481 & 1.2754 \\
\hline 0.995 & 0.1702 & 0.8835 & 0.4422 & 0.005 & 0.0239 & 0.1434 & 0.8327 \\
\hline 0.9975 & 0.2143 & 0.3688 & 1.7057 & 0.0025 & 0.4152 & 0.2143 & 0.4152 \\
\hline \multicolumn{4}{|c|}{ Silver futures } & \multicolumn{4}{|c|}{ Silver futures } \\
\hline 0.95 & 1.7238 & 1.8768 & 1.2913 & 0.05 & $7.8358^{+++}$ & $4.4933^{++}$ & 0.2251 \\
\hline 0.975 & $3.9665^{++}$ & 1.5482 & 1.2167 & 0.025 & 1.3501 & 0.1822 & 2.2047 \\
\hline 0.99 & $6.8661^{+++}$ & 6.7459 & 0.5354 & 0.01 & 0.8892 & 0.1786 & 1.7870 \\
\hline 0.995 & 2.3576 & 1.6577 & 0.8835 & 0.005 & 1.3350 & $8.24 \mathrm{e}-05$ & $29.737^{+++}$ \\
\hline 0.9975 & 0.7583 & 1.3524 & 0.7583 & 0.0025 & 0.4152 & 0.3855 & $33.325^{+++}$ \\
\hline
\end{tabular}

Notes: The table reports the empirical statistics of the Kupiec test that examines whether the empirical failure rate is equal to the pre-specified $\mathrm{VaR}$ level. The bold face numbers indicate the rejection of the null hypothesis at the $1 \%\left({ }^{+++}\right), 5 \%\left({ }^{++}\right)$and $10 \%\left({ }^{+}\right)$. The best model is the one with the least rejections.

\subsection{VaR forecasts and daily capital charges under the Basel II Accord}

Table 11 reports the percentage of the empirical number of violations and the average daily capital requirements over the forecasting period from January 1, 2010 to March 31, 2011, using our $\mathrm{VaR}$ forecasts derived from different GARCH-type models for the eight commodities 
under consideration. Our forecasting period totalizes 315 observations, but the daily capital charges are computed for only 65 rolling windows as they require the estimation of the number of violations over the previous 250 trading days.

Table 11

Percentage of violations and daily capital charges under the Basel II Accord

\begin{tabular}{|c|c|c|c|c|}
\hline \multirow{2}{*}{ Model } & \multirow{2}{*}{ Percentage of violations } & \multicolumn{3}{|c|}{ Daily capital charges } \\
\hline & & Mean & Minimum & Maximum \\
\hline \multicolumn{5}{|c|}{ Spot crude oil } \\
\hline GARCH & 0.3185 & 0.1543 & 0.1369 & 0.1839 \\
\hline EGARCH & 0 & 0.1724 & 0.1501 & 0.2042 \\
\hline FIAPARCH & 0 & 0.1613 & 0.1404 & 0.1866 \\
\hline \multicolumn{5}{|c|}{ Crude oil futures } \\
\hline GARCH & 1.2739 & 0.1312 & 0.1159 & 0.1514 \\
\hline EGARCH & 0.9554 & 0.1388 & 0.1161 & 0.1595 \\
\hline FIAPARCH & 0.3185 & 0.1414 & 0.1244 & 0.1730 \\
\hline \multicolumn{5}{|c|}{ Spot natural gas } \\
\hline GARCH & 0.9554 & 0.2902 & 0.1992 & 0.6990 \\
\hline EGARCH & 0.9554 & 0.2844 & 0.2031 & 0.6042 \\
\hline FIAPARCH & 0.9554 & 0.2819 & 0.1910 & 0.6736 \\
\hline \multicolumn{5}{|c|}{ Natural gas futures } \\
\hline GARCH & 0 & 0.1968 & 0.17702 & 0.2363 \\
\hline EGARCH & 0 & 0.2036 & 0.1848 & 0.2334 \\
\hline FIAPARCH & 0 & 0.2011 & 0.1687 & 0.2512 \\
\hline \multicolumn{5}{|l|}{ Spot gold } \\
\hline GARCH & 0.3077 & 0.0872 & 0.0668 & 0.1089 \\
\hline EGARCH & 0.3077 & 0.0870 & 0.0697 & 0.0988 \\
\hline FIAPARCH & 0.3077 & 0.0856 & 0.0670 & 0.0978 \\
\hline \multicolumn{5}{|l|}{ Gold futures } \\
\hline$\overline{\text { GARCH }}$ & 1.2307 & 0.0838 & 0.0659 & 0.1020 \\
\hline EGARCH & 0.9231 & 0.0818 & 0.0666 & 0.0930 \\
\hline FIAPARCH & 0.9231 & 0.0834 & 0.0693 & 0.0951 \\
\hline \multicolumn{5}{|l|}{ Spot silver } \\
\hline GARCH & 0.9231 & 0.1637 & 0.1318 & 0.1926 \\
\hline EGARCH & 1.2307 & 0.1744 & 0.1459 & 0.2129 \\
\hline FIAPARCH & 0.9231 & 0.1665 & 0.1397 & 0.2029 \\
\hline \multicolumn{5}{|l|}{ Silver futures } \\
\hline GARCH & 0.9231 & 0.1639 & 0.1265 & 0.2014 \\
\hline EGARCH & 1.2307 & 0.1619 & 0.1302 & 0.1998 \\
\hline FIAPARCH & 0.6154 & 0.1610 & 0.1285 & 0.2038 \\
\hline
\end{tabular}

Notes: The bold face numbers indicate the most appropriate models in terms of minimum daily capital charges, and the italic numbers the most appropriate models with respect to the criterion of lowest number of violations.

The results show that number of violations for all the models and commodities is always less than 10 , which implies that these models do not lead to entry in the red zone. The average daily capital charges range from $8.56 \%$ (FIAPARCH model for spot gold) to $29.02 \%$ (GARCH model for spot natural gas) of the portfolio value. Moreover, in terms of the daily average capital charges, the FIAPARCH model that takes into account asymmetry and long memory is the second best model after the GARCH model as it yields in three out of eight cases the lowest capital charges. These cases are for spot natural gas, spot gold and silver futures. Interestingly, the GARCH model produces the lowest average capital charges in four out of eight commodity cases including spot crude oil, crude oil futures, natural gas futures and spot silver. However, the percentage of violations given by the GARCH model is higher 
than that of the FIAPARCH model in four out of eight cases, suggesting that the risk of entering in the red zone defined by the Basel II Accord is higher with the GARCH model.

Taken together, the results of GARCH and FIAPARCH models are very close in terms of daily capital charges, but the GARCH model produces more violations. To the extent that going into the red zone is an adverse event to financial institutions, for example, in terms of reputation or the need to use standard models that may result in higher daily capital charges in the future, the use of the FIAPARCH model instead of the GARCH model will imply a small effect on daily capital charges but will lead to lower propensity to entering in the red zone.

We can thus conclude that none of the three linear and nonlinear models that account for different stylized facts of commodities consistently fit both the lowest number of violations and the optimal capital charge (i.e., the lowest capital requirement) of the Basel II Accord. FIAPARCH however gives the lowest number of violations for all the spot and futures prices of the commodities considered. Therefore, financial institutions should have more interest in applying the FIAPARCH model to forecast $\mathrm{VaR}$ and determine the daily minimum capital charges in compliance with the Basel II Accord.

\section{Conclusion}

This article examines the relevance and usefulness of long memory and asymmetry in modeling and forecasting the conditional volatility and market risk for the four most widely traded commodities - oil, natural gas, gold and silver. By adopting the GARCH-type methodology, our empirical framework allows to not only identify the best volatility model as it has been done in several past studies (e.g., Kang et al., 2009; Cheong, 2009), but also to investigate the ability of competing GARCH-type models to forecast the market risk (the VaR) associated with commodity markets as well as their suitability for the determination of daily capital charges of financial institutions under the Basel II Accord. In contrast to existing studies, our sample is extended to also cover the spot and futures prices of the four commodities, and we also consider a broader set of seven linear and nonlinear GARCH-type models (GARCH, IGARCH, EGARCH, RiskMetrics, FIGARCH, FIAPARCH and HYGARCH).

Regarding the empirical results, we find that no single GARCH-type model absolutely outperforms the others over both the in-sample and out-of-sample periods, even though nonlinear GARCH models, particularly the EGARCH and FIAPARCH models, achieve superior performance to linear GARCH models. Interestingly, our in-sample and out-of-sample VaR 
estimations show that the FIAPARCH provides better forecasting accuracy than do the next best models (GARCH and EGARCH) identified by the volatility forecast analysis. Thus, not only the long memory but also the asymmetric effects are important for modeling and forecasting the conditional volatility of the commodities we studied.

The correct choice of a GARCH-type specification appears to be a challenging task. This challenge should give better opportunities for more active arbitrage in the commodity markets and require market participants to check the relevance of a particular GARCH-type model before making use of it. To some extent, our results support the Basel Accord's tolerance for financial institutions to build their own models to forecast the VaR as none of our empirical GARCH models outperforms the others in terms of both the percentage of violations and capital requirements. Financial institutions should, however, prefer the FIAPARCH model as it produces the lowest number of violations for all the commodities considered.

The relevant models show evidence of asymmetry in the four commodity markets. This implies that model builders should favor models that cater for asymmetry when they examine commodity markets. Accordingly, policymakers should be aware that negative shocks such as recessions, wars and surges in geopolitical risk have stronger effects on conditional volatility than positive shocks such as new discoveries or improvement in the economy, with the exception of gold as explained below. The relevant models also show that the commodity markets are characterized by long memory which suggests that models like FIGARCH, FIAPARCH and HYGARCH are preferred to those like GARCH and IGARCH.

The results also show that the precious metals, gold and silver, are different from crude and oil when it comes to modeling returns and asymmetry. We find evidence of a significant return predictability for futures returns in case of the FIAPARCH model and the case is stronger for silver than gold. This implies lower persistence and faster mean-reversion in gold and silver returns, and more suitability in using the FIAPARCH model over the family of the GARCH models. Interestingly, we document that the impact of positive shocks on conditional volatility is greater than that of negative shocks. 


\section{References}

Agnolucci, P., 2009. Volatility in crude oil futures: A comparison of the predictive ability of GARCH and implied volatility models. Energy Economics 31, 316-321.

Aloui, C., Mabrouk, S., 2010. Value-at-risk estimations of energy commodities via long-memory, asymmetry and fat-tailed GARCH models. Energy Policy 38, 2326-2339.

Arouri, M., Hammoudeh, S., Lahiani, A., Nguyen, D. K., 2012a. Long memory and structural breaks in modeling the return and volatility dynamics of precious metals. Quarterly Review of Economics and Finance 52 (2012), 207-218.

Arouri, M., Lahiani, A., Lévy, A., Nguyen, D.K., 2012b. Forecasting the conditional volatility of oil spot and futures prices with structural breaks and long memory models. Energy Economics 34(1), 283 293.

Baillie, R., Bollerslev, T., Mikkelsen, H., 1996. Fractionally integrated generalized autoregressive conditional heteroskedasticity. Journal of Econometrics 74, 3-30.

Basel Committee on Banking Supervision, 1996. Supervisory framework for the use of "backtesting" in conjunction with the internal model-based approach to market risk capital requirements. Bank for International Settlements, Basel, Switzerland.

Basel Committee on Banking Supervision, 2004. International convergence of capital measurement and capital standards. Bank for International Settlements, Basel, Switzerland.

Baur, D.G., McDermott, T.K., 2010. Is gold a safe haven? International evidence. Journal of Banking and Finance 34, 1886-1898.

Bollerslev, T., 1986. Generalized autoregressive conditional heteroskedasticity. Journal of Econometrics 31, 307-327.

Brook, C., Burke, S.P., 2003. Information criteria for GARCH model selection: An application to high frequency data. European Journal of Finance 9, 557-580.

Browne, F., Cronin, D., 2010. Commodity prices, money and inflation. Journal of Economics and Business 62, 331-345.

Cheng, W.H., Hung, J.C., 2011. Skewness and leptokurtosis in GARCH-typed VaR estimation of petroleum and metal asset returns. Journal of Empirical Finance 18, 160-173.

Cheong, C.W., 2009. Modeling and forecasting crude oil markets using ARCH-type models. Energy Policy 37, 2346-2355.

Chkili, W., Aloui, C., Nguyen, D.K., 2012. Asymmetric effects and long memory in dynamic volatility relationships between stock returns and exchange rates. Journal of International Financial Markets, Institutions and Money 22, 738-757.

Choi, K., Hammoudeh, S., 2009. Long memory in oil and refined products markets. Energy Journal 30, 97-116.

Cochran, S.J., Mansur, I., Odusami, B., 2012. Volatility persistence in metal returns: A FIGARCH approach. Journal of Economics and Business 64, 287-305.

Cologni, A., Manera, M., 2009. The asymmetric effects of oil shocks on output growth: A markovswitching analysis for the G-7 countries. Economic Modelling 26, 1-29.

Conrad, C., Haag, B.R., 2006. Inequality constraints in the Fractionally Integrated GARCH model. Journal of Financial Econometrics 4, 413-449.

Creti, A., Joëts, M., Mignon, V., 2013. On the links between stock and commodity markets' volatility. Energy Economics 37, 16-28.

Dahl, C.M., Iglesias, E.M., 2009. Volatility spill-overs in commodity spot prices: new empirical results. Economic Modelling 26, 601-607. 
Davidson, J., 2004. Moment and memory proprieties of linear conditional heteroscedasticity models, and a new model. Journal of Business and Economic Statistics 22, 16-29.

Domanski, D., Heath, A., 2007. Financial investors and commodity markets. BIS Quarterly Review, 53-67.

Dwyer, A., Gardner, G., Williams, T., 2011. Global commodity markets-price volatility and financialisation. Reserve Bank of Australia Bulletin, June, 49-57.

Elder, J., Serletis, A., 2008. Long memory in energy futures prices. Review of Financial Economics 17, 146-155.

Engle, R.F., Bollerslev, T., 1986. Modelling the persistence of conditional variances. Econometric Reviews 5, 1-50.

Ewing, B.T., Malik, F., Ozfidan, O., 2002. Volatility transmission in the oil and natural gas markets. Energy Economics 24, 525-538.

Fong, W.M., See, K.H., 2002. A Markov switching model of the conditional volatility of crude oil futures prices. Energy Economics 24, 71-95.

Geweke, J., Porter-Hudak, S., 1983. The estimation and application of long-memory time series models. Journal of Time Series Analysis 4, 221-238.

Giot, P., Laurent, S., 2003. Market risk in commodity markets: a VaR approach. Energy Economics 25, 437-457.

Hamilton, J.D., 1996. Specification testing in Markov-switching time series models. Journal of Econometrics 70, 127-157.

Hammoudeh, S., Dibooglu, S., Aleisa, E., 2004. Relationships among US oil prices and oil industry equity indices. International Review of Economics and Finance 13(3), 427-453.

Hammoudeh, S., Malik, F., McAleer, M., 2011. Risk management of precious metals. Quarterly Review of Economics and Finance 51, 435-441.

Hammoudeh, S., Yuan, Y., McAleer, M., Thompson, M., 2010. Precious metals-exchange rate volatility transmissions and hedging strategies. International Review of Economics and Finance 20, 633-647.

Hammoudeh, S., Yuan. Y., 2008. Metal volatility in presence of oil and interest rate shocks. Energy Economics 30, 606-620.

Holmes, M.J., Wang, P., 2003. Oil and the asymmetric adjustment of the UK output: a Markov switching approach. International Review of Applied Economics 17, 181-192.

Hung, J.C., Lee, M.C., Liu, H.C., 2008. Estimation of value-at-risk for energy commodities via fattailed GARCH models. Energy Economics 30, 1173-1191.

Kang, S.H., Cheong, C., Yoon, S.M., 2010. Long memory volatility in Chines stock markets. Physica A $389,1425-1433$.

Kang, S.H., Kang, S.M., Yoon, S.M., 2009. Forecasting volatility of crude oil markets. Energy Economics 31, 119-125.

Kang, S.H., Yoon, S-M., 2013. Modeling and forecasting the volatility of petroleum futures prices. Energy Economics 36, 354-362.

Kasman, A., Kasman, S., Torun, E., 2009. Dual long memory propriety in returns and volatility: Evidence from the CEE countries's stock markets. Emerging Markets Review 10, 122-139.

Kupiec, P., 1995. Technique for verifying the accuracy of risk measurement models. Journal of Derivatives 2, 173-184.

Mabrouk, S., Saadi, S., 2012. Parametric Value-at-Risk analysis: Evidence from stock indices. Quarterly Review of Economics and Finance 52, 305-321. 
McMillan, D.G., Ruiz, I., 2009. Volatility persistence, long memory and time-varying unconditional mean: Evidence from 10 equity indices. Quarterly Review of Economics and Finance 49, 578-595.

Mohammadi, H., Su, L., 2010. International evidence on crude oil price dynamics: applications of ARIMA-GARCH models. Energy Economics 32, 1001-1008.

Niu, H., Wang, J., 2013. Volatility clustering and long memory of financial time series and financial price model. Digital Signal Processing 23, 489-498.

Oh, G., Kim, S., Eom, C., 2008. Long-term memory and volatility clustering in high-frequency price changes. Physica A 387, 1247-1254.

Regnier, E., 2007. Oil and energy price volatility. Energy Economics 29, 405-427.

Robinson, P.M., 1995. Log-periodogram regression of time series with long range dependence. Annals of Statistics 23, 1048-1072.

Sadorsky, P., 2006. Modeling and forecasting petroleum futures volatility. Energy Economics 28, 467488.

Silvennoinen, A., Thorp, S., 2013 Financialization, crisis and commodity correlation dynamics, Journal of International Financial Markets, Institutions and Money 24, 42-65.

Tang, T.L., Shieh, S.J., 2006. Long memory in stock index futures markets: A value-at-risk approach. Physica A 366, 437-448.

Tansuchat, R., Chang, C-L., McAleer, M., 2009. Modelling long memory volatility in agricultural commodity futures. CIRJE-F-680 Working Paper. http://hdl.handle.net/2261/32452.

Thuraisamy, K.S., Sharma, S.S., Ahmed, H.J.A., 2013. The relationship between Asian equity and commodity futures markets. Journal of Asian Economics, in press.

Tse, Y., 1998. The conditional heteroscedasticity of the yen-dollar exchange rate. Journal of Applied Econometrics 13, 49-55.

Tully, E., Lucey, B.M., 2007. A power GARCH examination of the gold market. Research in International Business and Finance 21, 316-325.

Vivian, A., Wohar, M.E., 2012. Commodity volatility breaks. Journal of International Financial Markets, Institutions and Money 22, 395-422.

Wang, Y., Wu, C., Wei, Y., 2011. Can GARCH-class models capture long memory in WTI crude oil markets? Economic Modelling 28, 921-327.

Wei, Y., Wang, Y., Huang, D., 2010. Forecasting crude oil market volatility: further evidence using GARCH-class models. Energy Economics 32, 1477-1484.

Zivot, E., Andrews, K., 1992. Further evidence on the great crash, the oil price shock, and the unit root hypothesis. Journal of Business and Economic Statistics 10, 251-270. 